\title{
Elaboración de un programa de atención temprana
}

\author{
Isidoro Candel Gil
}

Equipo de Atención Temprana de Murcia

España 


\section{Resumen}

En el siguiente trabajo se presentan los principales instrumentos de evaluación en atención temprana, y se reflexiona sobre su empleo, teniendo en cuenta que han sido creados con y para población normativa. Asimismo, se describen las características evolutivas de algunos colectivos infantiles entre los que destacan el síndrome de x frágil, el síndrome de Williams y el síndrome de Prader Willi.

A continuación, entrando en el terreno de la intervención, se describen los objetivos principales que debe perseguir la programación de cada una de las áreas en atención temprana (motora, perceptivo-cognitiva, socio-comunicativa y de autonomía personal).

Por último, se introducen importantes reflexiones acerca del papel de los padres en todo el proceso, así como algunas consideraciones prácticas a la hora de poner en práctica estos programas.

Palabras clave: atención temprana, evaluación, intervención motora, perceptivo-cognitiva, socio-comunicativa, autonomía personal. 


\section{La evaluación}

En un programa de atención temprana (AT), los objetivos de la evaluación son desarrollar unos objetivos individuales y familiares adecuados con el fin de dirigir el desarrollo de la programación individual; proporcionar información a los padres y a los profesionales acerca de los progresos del niño y facilitar información que permita determinar el valor de un sistema de intervención.

No se puede negar que la evaluación de la conducta infantil presenta numerosos problemas, que se ven acrecentados en el caso de los niños más pequeños y en los que, además, presentan algún tipo de déficit o alteración. De ahí que se hayan criticado las aproximaciones de evaluación más tradicionales, entre otras cosas porque la situación de test, al ser muy artificial, puede no sacar a flote el verdadero potencial del niño en un momento determinado, o bien porque da la sensación de que lo único que se busca es una cifra para situar o etiquetar al niño.

La evaluación en la primera infancia es una especialidad que actualmente está en transformación. Dominada desde sus comienzos por los modelos psicométricos y por estrategias de medida utilizadas con niños mayores y con adultos, empieza a fraguarse ahora una metodología que es exclusiva para los niños muy pequeños (Meisels y Atkins-Burnett, 2000). Conviene, por tanto, analizar algunos aspectos de interés, con el fin de actualizar procedimientos y cambiar actitudes para hacer esta tarea más eficaz.

La mayoría de los programas de AT centran sus evaluaciones en las áreas cognitiva, de lenguaje y motora, al dar por hecho que la estimulación en estas áreas constituye el objetivo prioritario de la intervención. De esta forma, se omiten, o en el mejor de los casos, se despachan rápidamente otros aspectos de enorme importancia, como los psicosociales, los afectivoemocionales, o los familiares (Cicchetti y Wagner, 1990; McCune, Kalmanson, Fleco y otros, 1990; Barnard y Kelly, 1990). Para comprender mejor la competencia del niño y su relación con su entorno socio-familiar, hay que ampliar el abanico de la exploración, buscando información en estas tres dimensiones: 
$1^{\text {a }}$ La organización evolutiva del niño: habilidades comunicativas, desarrollo socioemocional, procesos cognitivos, estilo de aprendizaje, capacidad de respuesta al medio, habilidades de juego.

$2^{\mathrm{a}}$ Las características de su entorno familiar y social.

$3^{\mathrm{a}}$ La relación entre el niño y su entorno: interacción padres-niño.

En lugar de centrarnos tanto en los cocientes de desarrollo y en los datos de los tests o de los inventarios del desarrollo, hemos de prestar mayor atención a los aspectos de interacción entre el niño y su medio ambiente, y examinar las conductas funcionales y las habilidades de solución de problemas que sirvan al niño para su adaptación a las situaciones reales de cada día. Se trata, en consecuencia, de prestar más importancia a los aspectos cualitativos de la evaluación, no poniendo tanto énfasis en lo que el niño hace (resultado), sino más bien en cómo lo hace (proceso): nivel de conexión con el medio físico y social, tipo de relación o interacción, interés hacia el medio, nivel de motivación, atención a los estímulos y a las actividades, nivel de actividad motora, capacidad de respuesta, manipulación y exploración de los materiales, respuestas de evitación, gustos y preferencias hacia actividades o materiales determinados, estilo de conducta (planificador, impulsivo, atento, disperso, constante, inhibido, activo, espontáneo, dependiente...).

También nos interesa, en esta línea, registrar algunos aspectos socio-cognitivos del niño, como contacto ocular, habilidades de comunicación, características del juego, capacidad de influir sobre el ambiente, habilidad de solución de problemas, etc. Es importante hacer observaciones del comportamiento del niño cuando está solo, acompañado de los padres, o en grupo (si es mayorcito). Lo que importa realmente, por tanto, no es obtener una cifra determinada, sino conocer las habilidades y los puntos débiles del niño, sus características generales, con el fin de ajustar el programa de intervención a sus necesidades reales y a las de su familia.

No es raro que muchos niños con alguna problemática en su desarrollo no reaccionen a los estímulos y materiales de una prueba determinada. Hemos de reconocer que el material "obligatorio" de muchos tests es poco atractivo y les dice poco a muchos niños. Esto provoca una inhibición cuando no un rechazo a las actividades planteadas, lo cual no significa que el niño no posea la capacidad que se trata de elicitar. Pensemos que lo que las pruebas plantean son situaciones-estímulo a las que debe responder el niño. A veces habrá que recurrir a otros 
planteamientos menos estandarizados, más funcionales, que tengan un mayor significado para el niño y despierten su interés. Es decir, no nos fijemos tanto en la "ortodoxia" del test, y centrémonos más en conocer, de verdad, cuáles son las posibilidades, las potencialidades, las características del niño que tenemos entre manos, aun a costa de pecar un poco de "heterodoxos". La experiencia nos dice que, muchas veces, hemos de echar mano a una serie de situaciones-estímulo tomadas de diversas pruebas, y de la observación de las conductas espontáneas de los niños, con el fin de conocer sus capacidades y características.

En el proceso de la evaluación no sólo es importante recoger información sobre las conductas del niño en respuesta a unos estímulos determinados, sino que también hemos de registrar las conductas que van surgiendo de forma espontánea, que a veces no figuran en las hojas de respuesta de las escalas de desarrollo, pero que nos arrojan mucha luz sobre la situación del niño y de su familia.

Generalmente la evaluación tradicional suele llevarse a cabo en un contexto excesivamente artificial. No tiene ningún sentido mantener algunos usos y procedimientos que no se ajustan a la realidad que intentamos examinar. En consecuencia, podemos recurrir a algunas formas alternativas que nos aportan una información más rica y objetiva: observar el juego del niño con la madre, proponer situaciones naturales menos dirigidas con materiales familiares para el niño, introducir en la acción a algún hermano o a un niño, recoger información de los padres u otros miembros de la familia. Debemos reconocer que la situación diádica (niñoexaminador) de la evaluación como la hacemos en la actualidad no es el mejor modo de obtener información y, por tanto, no debemos desdeñar esas alternativas.

Por otra parte, a la hora de evaluar a un niño discapacitado, de alto riesgo, o con algún problema en su desarrollo, no podemos perder de vista que estamos utilizando los mismos instrumentos que para un niño no deficiente, y que estos instrumentos han sido baremados con niños cuyos sentidos están intactos y cuyo sistema nervioso no tiene alteraciones. Por lo tanto, cuando obtenemos un determinado nivel de desarrollo, hemos de ser prudentes y no establecer comparaciones exactas respecto al funcionamiento de un niño normal del mismo nivel evolutivo. Y, además, debemos tener muy presentes las características peculiares que, en no pocas ocasiones, presentan los niños con problemas de desarrollo. Las pruebas más utilizadas en la actualidad con niños entre 0 y 6 años son: 
¿ Escala para la Evaluación de la Conducta del Recién Nacido de Brazelton. No es una evaluación neurológica propiamente dicha, aunque las implicaciones neurológicas de una escala de este tipo hacen necesaria la inclusión de unos temas neurológicos básicos. El principal contenido de la evaluación es conductual: se trata de un intento de puntuar las respuestas válidas del niño a su medio y, de manera indirecta, su efecto sobre el medio. La nueva versión de la Escala consta de 18 ítems neurológicos y 37 conductuales.

- Escalas Bayley de Desarrollo Infantil (BSID). Consta de dos escalas, la Mental y la de Psicomotricidad, aplicables de 1 a 30 meses. La Escala Mental evalúa la agudeza sensoperceptiva, la discriminación y la capacidad de respuesta a estímulos, la adquisición temprana de permanencia del objeto y de la memoria, el aprendizaje y la capacidad de resolución de problemas, las vocalizaciones al comienzo de la comunicación verbal, y la capacidad temprana para generalizar y clasificar. Los resultados se expresan en puntuaciones típicas o Índices de Desarrollo Mental (IDM). La Escala de Psicomotricidad proporciona una medida del grado de control del cuerpo, la coordinación de los músculos grandes y las habilidades manipulativas de manos y dedos. Sus resultados se expresan en Índices de Desarrollo Psicomotriz (IDP). Hay una edición más actualizada de estas Escalas, con algunas mejoras, que todavía no está comercializada en España.

- Escala para medir el desarrollo psicomotor de la primera infancia Brunet-Lèzine. Aplicable de 0 a 6 años, esta Escala evalúa cuatro áreas: Control postural y motricidad; Coordinación óculo-motriz y adaptación a objetos; Lenguaje; Sociabilidad o relaciones sociales y personales. Los resultados se expresan en Edad de Desarrollo Global y Cociente de Desarrollo Global; además se obtienen Edades de Desarrollo y Cocientes de Desarrollo por las distintas áreas.

- Escala de Uzgiris y Hunt. La Escala, que evalúa el desarrollo sensorio-motor, es aplicable desde 1 a 24 meses. Se divide en siete subescalas: Seguimiento visual y permanencia del objeto; Desarrollo de medios para alcanzar fines; Imitación vocal; Imitación gestual; Causalidad operacional; Relaciones espaciales; Desarrollo de esquemas de acción. La Escala original de Uzgiris y Hunt se complementa con un interesante trabajo de Carl Dunst, que introdujo una serie de ítems en cada una de las subescalas (los ítems experimentales) y la posibilidad de elaborar un perfil sensoriomotor.

口 Inventario de Desarrollo Battelle. Aplicable de 0 a 8 años. Evalúa las habilidades fundamentales del desarrollo del niño en las áreas tradicionales, ofreciendo el nivel de desarrollo. 
\ Escalas McCarthy de Aptitudes y Psicomotricidad para niños. Su edad de aplicación va desde los 2;6 años hasta los 8;6 años. Evalúa el nivel intelectual general y sus puntos fuertes y débiles en las variables aptitudinales más importantes: verbal, perceptivo-manipulativa, numérica, memoria y psicomotricidad. Se obtienen puntuaciones que se transforman en un Índice General Cognitivo, que se puede convertir en edad equivalente.

ـ Escala Reynell para evaluar el desarrollo del lenguaje. Aplicable desde 18 meses a 4;6 años, evalúa la capacidad de comprensión y expresión verbal, permitiendo determinar el nivel evolutivo del niño. Se puede utilizar también con niños deficientes auditivos.

- Escala Adaptativa de Wisconsin. Se aplica desde 0 a 48-60 meses. Dispone de unas edades de referencia que permiten situar el nivel de desarrollo del niño en las siguientes áreas: Juego y Socialización; Comida; Control de esfinteres; Vestido; Aseo (lavado de manos y cara, dientes, baño, peinado); Motora gruesa; Motora fina; Cognitiva; Lenguaje receptivo; Lenguaje expresivo.

- Batería Kaufman para niños (K-ABC). Esta Batería de evaluación es un instrumento para medir la inteligencia y el logro en niños de 2;6 a 12;6 años de edad. Comprende cinco escalas globales: Escala de Procesamiento Secuencial, Escala de Procesamiento Simultáneo; Procesamiento Mental Compuesto (una combinación de las escalas de procesamiento secuencial y simultáneo, proporcionando una estimación global del funcionamiento intelectual); Escala de Logro; y Escala no Verbal.

Desde hace unos pocos años se viene trabajando en la elaboración y aplicación de instrumentos de evaluación neuropsicológica para niños, aunque son muy escasas las pruebas diseñadas específicamente para valorar la función neuropsicológica en la infancia ( 0 a 2 años). Sin embargo, como apunta Aylward (1997), se puede recoger información neuropsicológica de otros instrumentos que tienen una orientación evolutiva, como los que hemos reseñado más arriba. La combinación de datos evolutivos y neurológicos es necesaria cuando se emplean en la evaluación neuropsicológica los tests diseñados con otros propósitos. Repasemos las principales características de dos instrumentos con una perspectiva neuropsicológica:

- Early Neuropsychologic Optimatily Rating Scales (ENORS) (Aylward, 1994). Se aplica a ciertas edades clave: 3, 6, 9, 12, 18 y 24 meses. Los items de la Escala se agrupan en los siguientes apartados: Función/Integridad neurológica básica, Funciones receptivas, Funciones expresivas (motricidad fina), Funciones expresivas (motricidad oral), Funciones expresivas (motricidad gruesa), Procesamiento, y Actividad mental. Los 
ítems se puntúan mediante tres métodos: observación, elicitación e información del cuidador principal del niño.

- Bayley Infant Neurodevelopmental Screener (BINS) (Aylward, 1995). Permite una evaluación de la postura, el tono, el movimiento, el estatus evolutivo y la integridad neurológica en niños de 3 a 24 meses, haciéndose una valoración de cuatro áreas conceptuales: Función/Integridad neurológica básica, Funciones receptivas, Funciones expresivas, y Procesos cognitivos.

- NEPSY (Korkman, Kirk y Kemp, 1997). Es un instrumento comprehensivo diseñado para evaluar el desarrollo neuropsicológico de niños en edad preescolar y escolar. Incorpora un amplio rango de subtests para evaluar el desarrollo neuropsicológico en cinco dominios funcionales: 1. Funciones de atención y ejecutivas; 2. Lenguaje; 3. Funciones sensoriomotrices; 4. Procesamiento visoespacial; y 5. Memoria y aprendizaje. Con el NEPSY los tipos de evaluación más comunes que efectuamos son: a) Una evaluación básica para obtener una visión del estatus neuropsicológico del niño; b) Una evaluación ampliada o selectiva para un análisis más detallado de trastornos cognoscitivos concretos; y, c) Una valoración completa para una evaluación neuropsicológica comprehensiva.

El mayor énfasis que se viene haciendo en la participación de la familia en los programas de AT ha ocasionado que se empiece a prestar mayor atención a la evaluación de distintos aspectos del contexto familiar, y a la relación que hay entre el niño y su entorno. Pueden señalarse tres razones de la importancia de la evaluación familiar (Krauss, 2000): $1^{\text {a }}$ Esta evaluación reconoce de forma explícita la necesidad de examinar el desarrollo del niño en su contexto más importante, que es la familia; $2^{\mathrm{a}}$ La evaluación familiar se basa en la creencia de que los padres pueden beneficiarse de la atención que se les presta a la hora de contar con ellos en el desarrollo y crianza de sus hijos; y, $3^{\mathrm{a}}$ La intensidad y la especificidad de los programas de AT necesitan adaptarse a las características y al funcionamiento de la familia.

El objetivo de esta evaluación familiar es identificar la forma en que puede proporcionarse la ayuda externa, que mejore las habilidades naturales o adquiridas de la familia para estimular el desarrollo y la crianza de su hijo con problemas de desarrollo o de alto riesgo. En su forma tradicional, la evaluación familiar implica un proceso de valoración y juicio profesional sobre las capacidades y debilidades de la familia, con el fin de proporcionar un ambiente óptimo para el desarrollo y crecimiento de su hijo. Desde una perspectiva más 
actual, basándonos en la fundamentación teórica más influyente en estos momentos (Bronfenbrenner, Dunst, Pearlin, Sameroff, Guralnick), uno de los propósitos de la evaluación familiar en los programas de AT es identificar los factores de riesgo y de protección en el ambiente más próximo al niño. Otro aspecto tiene que ver con la mejora de las redes de apoyo a los padres y la ayuda para que se conviertan en cuidadores más hábiles de sus hijos. Un tercer aspecto hace referencia a la naturaleza y forma de las interacciones entre la familia y los profesionales que prestan los servicios (Candel, 2005a).

La evaluación no es algo que se hace "a" la familia o "en" la familia, sino algo que se realiza "con" la familia. La evaluación no es un proceso para exponer las deficiencias de la familia, sino, más bien, para identificar sus objetivos. No trata de proporcionar una prescripción, una receta, para remediar los problemas de la familia; ayuda a crear un acuerdo entre los profesionales de la AT y la familia sobre los tipos de asistencia deseados, que son determinados por la familia. Con más propiedad, habría que hablar, por tanto, de "reunión de información familiar". Por eso, algunos autores ofrecen una serie de orientaciones para los profesionales, a fin de ayudarles en su aproximación a las familias. Beckman, Frank y Newcomb (1996) sugieren seis habilidades necesarias para establecer una relación con las familias: 1) Congeniar con la familia (escuchar sin juzgar); 2) Utilizar una escucha activa (escuchar lo que se dice y cómo se dice); 3) Utilizar las preguntas de forma eficaz (buscar un equilibrio entre las preguntas que requieren respuestas objetivas, y las que son abiertas o cerradas); 4) Reflejar y clarificar (repetir las frases y ampliar los comentarios de los padres); 5) Proporcionar información (ofrecer ayuda concreta); y, 6) Reconstruir (redefinir los problemas o la información de una forma positiva).

Para llevar a cabo la evaluación familiar contamos con algunos instrumentos, como los siguientes, que nos pueden ser de utilidad:

- Inventario HOME para familias de niños pequeños y de edad preescolares, de Caldwell y Bradley.

- Escala de funcionamiento familiar, de Deal, Trivette y Dunst.

- Escalas para evaluar los estilos de interacción de los padres, de Dunst.

- Cuestionario de recursos y estrés, de Friedrich, Greenberg y Crnic.

- Escala de recursos familiares, de Lest y Dunst.

- Escala para evaluar las oportunidades de juego padres-niño, de Dunst. 
- Indice de bienestar personal, de Trivette y Dunst.

口 Escala de apoyo familiar, de Dunst, Jenkins y Trivette.

口 Parenting Stress Index, de Abidin.

\section{¿Desarrollo igual o diferente? Características evolutivas en algunas deficiencias}

En la intervención con niños que tienen necesidades educativas especiales, el punto de partida en el diseño de los currículos viene dado por los modelos o descripciones del desarrollo del niño normal. Los estudios más recientes han mostrado que los niños con una deficiencia mental exhiben procesos similares en su adquisición de habilidades sensoriomotoras, al compararlos con los niños que no presentan problemas en su desarrollo (Dunst, 1990 y 1998). Aunque este punto de referencia parece, de antemano, razonable, no podemos olvidar que recientes investigaciones insisten en que el desarrollo de los niños con alguna discapacidad o situación de alto riesgo no es simplemente igual al de los niños no deficientes, sino que presenta algunas diferencias cualitativas dignas de ser tenidas en cuenta.

No es extraño que, siguiendo una corriente muy actual en la investigación sobre discapacidad, se hable de un fenotipo conductual en el caso de diversas alteraciones genéticas. Los fenotipos conductuales significan que las personas que tengan un determinado síndrome muestran ciertas consecuencias en su conducta y desarrollo, con una mayor probabilidad o posibilidad que las personas que no tienen dicho síndrome. Aunque muchas personas con una discapacidad intelectual concreta de causa genética mostrarán la conducta o conductas características de ese síndrome, raro será que la muestren todas y cada una de ellas; como tampoco todas las que la muestran lo harán en el mismo grado o nivel de gravedad, o incluso en el mismo momento de su desarrollo. Es decir, que los trastornos genéticos se conceptualizan como elementos que predisponen a la persona a tener una $\mathrm{u}$ otra conducta relacionada con esa etiología (Hodapp y Dykens, 2004).

A este respecto, hemos de aclarar que la población más estudiada, pero no la única, es la de los niños con síndrome de Down, porque se trata de un grupo numeroso, detectado muy tempranamente, y etiológicamente homogéneo. Los hallazgos del reciente trabajo de Wishart (2002) sugieren que el proceso de desarrollo de los niños con síndrome de Down es, 
fundamentalmente, diferente, tanto en su naturaleza como en su curso. La autora supone que, si esto es así, entonces deberán tenerse en cuenta, a la hora de diseñar y llevar a la práctica los programas de AT y otras intervenciones educativas, las diferencias en el estilo de aprendizaje natural de los niños y en las vías por las que discurre su desarrollo.

A modo de ejemplo, y con una intención meramente ilustrativa, repasemos algunas de las características más comunes de los niños pequeños con síndrome de Down (SD), sin pretender, en ningún momento, que este listado tenga un carácter cerrado y obligatorio para todos los niños. Se recogen, más bien, los rasgos más señalados en la bibliografía, contrastados en la práctica (Dunst, 1990; Candel y Carranza, 1993; Wishart, 1997; Candel, 2005b):

- El desarrollo de la motricidad gruesa en los niños con SD está influido por una serie de características, como la hipotonía muscular, la laxitud de ligamentos, la reducción de la fuerza, la cortedad de los brazos y las piernas. Además, como se sabe, hay niños con SD que presentan problemas clínicos, como la cardiopatía, que limitan o condicionan de forma notable su desarrollo y su estimulación. Es frecuente, entonces, la torpeza motora gruesa y fina, la lentitud en las realizaciones motrices, la deficiente coordinación óculo-manual y dinámica, y las dificultades de equilibrio (Buceta y Fernández, 2004).

- La capacidad de respuesta y el interés a los estímulos ambientales de estos niños son, en general, inferiores a los exhibidos en niños no deficientes.

- Los niños con SD de 0 a 3 meses tardan más tiempo en fijar su mirada a estímulos visuales; sus respuestas de orientación a estímulos sonoros son lentas y están atrasadas; sus respuestas de habituación tardan más tiempo en aparecer; tienen un considerable retraso en el patrón de contacto ocular, lo cual implica deficiencias en algunos procesos cognitivos y en sus habilidades socio-comunicativas.

- Parece que los niños con SD no exhiben un déficit general de la atención, sino que, más bien, su organización de la atención más concentrada se limita a la situación social. Por tanto, si los niños con SD prefieren la interacción social a la manipulación de los objetos o, simplemente, están más interesados en el mayor nivel posible de actividad que es propio de los estímulos sociales, es probable que, si se les presenta el material de una forma más viva o animada, se concentrarán más que si el material se les presenta de una forma más pasiva. Ruskin y sus colaboradores (1994a, 1994b) 
dieron cuenta de dos estudios que son muy ilustrativos. En un primer trabajo sobre la motivación de logro, encontraron que los niños con síndrome de Down de 22 meses de edad cronológica parecen mostrar déficits en la implicación con la tarea, más que en la calidad de su juego. Según los autores, es posible que los patrones atípicos de implicación en la tarea y de placer en la causalidad, observados en estos niños, puedan dificultar su desarrollo cognitivo posterior. En un segundo trabajo, Ruskin y colaboradores encontraron que los niños con síndrome de Down no exhibían un déficit general de atención, sino que, más bien, su organización de la atención más concentrada se limitaba a la situación social.

- Suelen ser frecuentes los déficits en atención conjunta.

- Los niños con SD suelen presentar un déficit en la capacidad de exploración manual con tendencia a la conducta impulsiva.

- Los resultados del trabajo de Linn, Goodman y Lender (2000) muestran que los niños con SD con una edad media de 54 meses, pasan más tiempo en conducta pasiva, y cambian del juego a la pasividad y al revés, más a menudo que los niños normales. No hubo diferencias entre ambos grupos en cuanto al tiempo pasado en actividades sociales, pero los niños con SD manifestaban una mayor frecuencia de conducta social. Por otra parte, los niños con SD pasaban más tiempo en pasividad a medida que transcurría el tiempo de juego, mientras que en los normales pasaba al contrario.

- Tienen estrategias diferentes para asimilar e integrar la información. El hecho de que destaquen en codificación motora y decodificación visual, así como que tengan más dificultades en la memoria secuencial auditiva y en la velocidad de procesar esa información auditiva, aconseja un aprendizaje por imitación o modelado, resaltando los estímulos visuales.

- Suelen fracasar en la consolidación del conocimiento recientemente adquirido. Igualmente, tienden a un uso creciente de conductas de evitación cuando se enfrentan con retos nuevos o con aprendizajes por encima de su nivel. Presentan dificultades de adaptación a nuevas situaciones.

- Los niños con SD tienden a infrautilizar las habilidades adquiridas, con dificultades de generalización y con un bajo nivel de espontaneidad. Hay una resistencia creciente a tomar la iniciativa en el aprendizaje.

- Suele haber dificultad para pasar de un estadio sensoriomotor a otro, en especial del estadio IV al estadio V. 
- Retraso en las adquisiciones comunicativas y del lenguaje.

- Las adquisiciones socio-afectivas siguen patrones similares a los de los niños no deficientes, pero a un ritmo más lento y con una menor intensidad.

- Los niños con SD no suelen manifestar retrasos significativos en la adquisición de hábitos de autonomía personal.

Ahora vamos a analizar las principales características de los niños pequeños con otras alteraciones, que están siendo objeto de estudio en la actualidad.

\section{El síndrome de X frágil}

En el caso de los niños con síndrome X frágil (SXF) ${ }^{*}$, sabemos muy poco acerca de su desarrollo en los primeros meses o años de vida, por una razón muy simple: la edad media de detección del SXF se sitúa, en la actualidad, en torno a los 32 meses (para una revisión, ver Candel, 2004). Las primeras manifestaciones del SXF son la hipotonía y el retardo en las adquisiciones básicas, apareciendo ya desde el principio notables diferencias individuales, como se puede apreciar en la siguiente tabla

\section{Tabla 1. Edades de adquisición de distintas conductas por niños y niñas con síndrome $X$} frágil (Roberts y otros, 2001).

\begin{tabular}{|l|c|}
\hline \multicolumn{1}{|c|}{ CONDUCTA } & EDAD ADQUISICIÓN NIÑOS SXF \\
\hline Sedestación & 8 meses $(5-12 \mathrm{~m})$. \\
\hline Gateo & 11 meses $(6-13 \mathrm{~m})$. \\
\hline Marcha autónoma & 16 meses $(9-23 \mathrm{~m})$. \\
\hline Primera palabra & 28 meses $(9-88 \mathrm{~m})$. \\
\hline
\end{tabular}

También se han registrado diferencias por sexo, teniendo las niñas con SXF mejor evolución que los niños, ya que éstos sólo tienen un cromosoma X:

\footnotetext{
${ }^{*}$ El síndrome $\mathrm{X}$ frágil está considerado como la primera causa de retraso mental hereditario. Es una afección genética, cuya manifestación clínica guía es el retraso mental, y cuyo origen es la expansión de la tripleta formada por las bases nitrogenadas del ADN (citosina-guanina-guanina), debido a la inactivación del gen FRM1 (Fragil X Mental Retardation), situado en el locus Xq27.3.
} 
Tabla 2. Edades de adquisición de algunas conductas en niños y niñas con síndrome $X$ frágil (Artigas y otros, 2001; Puche, 2005).

\begin{tabular}{|l|c|c|c|c|}
\hline \multirow{2}{*}{ CONDUCTA } & \multicolumn{4}{|c|}{ EDAD ADQUISICIÓN NIÑOS Y NIÑAS SXF } \\
\cline { 2 - 5 } & \multicolumn{2}{|c|}{ Artigas y otros (2001) } & \multicolumn{2}{c|}{ Puche (2005) } \\
\cline { 2 - 5 } & NIÑOS & NIÑAS & NIÑOS & NIÑAS \\
\hline Marcha autónoma & 19.2 meses & 14.8 meses & 17 meses & 16 meses \\
\hline Primera palabra & 32 meses & 20 meses & 26 meses & 17 meses \\
\hline
\end{tabular}

Roberts, Hatton y Bailey (2001) observaron que sus habilidades de desarrollo evolucionan a medida que avanza la edad; asimismo, la proporción de crecimiento disminuye con el tiempo, existiendo notables diferencias en el grupo. Por ejemplo, a los 12 meses, la edad de desarrollo media era de 9 meses (un retraso de 3 meses), mientras que a los 36 meses era de 20,65 meses (un retraso de 15 meses). Los datos se recogen en la figura 1.

Figura 1. Puntuaciones totales de edad de desarrollo en el Inventario Batelle en niños con síndrome $X$ frágil (Roberts y otros, 2001).

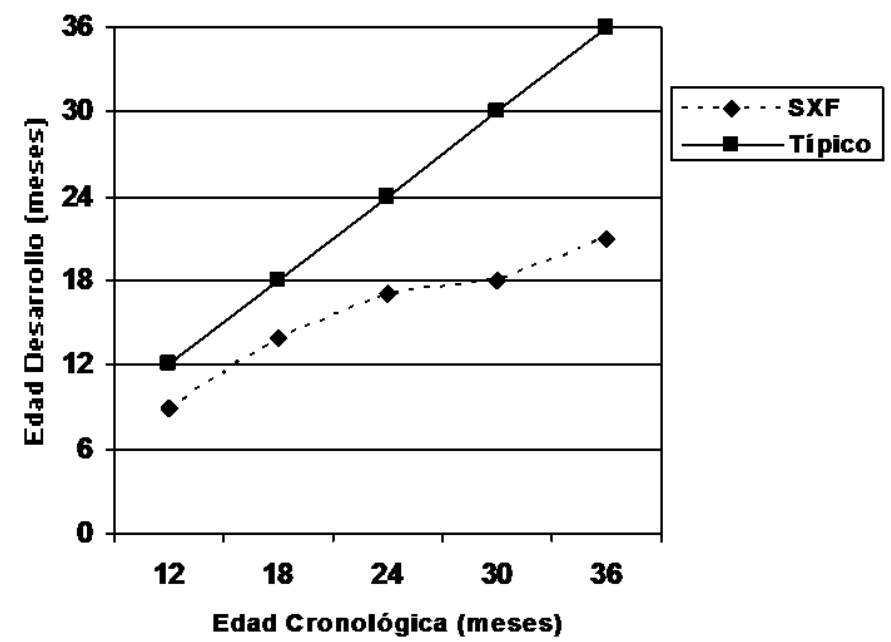

Los datos de Roberts y sus colaboradores son muy similares a los aportados por Hatton, Bailey, Roberts et al. (2000), quienes examinaron el desarrollo de 50 niños con SXF de 12 a 72 meses que seguían un programa de AT. Después de los 36 meses, continúan progresando las puntuaciones de edad de desarrollo, aunque a un ritmo más lento y alejándose cada vez más del desarrollo normativo; a los 72 meses, la diferencia entre ambos grupos se duplica: edad de desarrollo media de 36 meses para los niños con SXF. Parece comprobado 
que en los niños con SXF, el área de Comunicación es la más atrasada, mientras que la Motora es la más evolucionada.

Conviene detenerse un poco a comentar las características de los niños pequeños con SXF. Hatton y otros (2000) recogen las descripciones de los educadores de estos niños, que los califican como sociables y entusiastas, con unas habilidades de comunicación receptiva y no verbal relativamente buenas; tienen buen sentido del humor, buenas habilidades de imitación visual, y una buena capacidad de respuesta a las actividades estructuradas y rutinarias. La mayoría de los educadores opinaba que a los niños con SXF les costaba centrarse en las tareas, mostrando un período de atención corto (elevada tendencia a la distracción). Eran hiperactivos o extremadamente activos, con un alto nivel de ansiedad; tienden a sobreestimularse con facilidad, son impulsivos y muestran una cierta agresividad ligada a la frustración o a la ansiedad. Se les describe como aprendices fundamentalmente visuales, requiriendo actividades manipulativas estructuradas. Un hecho revelador aportado por Roberts y otros (2001) es que las conductas autistas se observaban en algunos sujetos de su muestra ya en el primer año de vida.

Los educadores de los niños con SXF pequeños consideraban que los dos aspectos principales a tener en cuenta al trabajar con ellos, eran: 1) desarrollar una rutina consistente con actividades estructuradas en un ambiente organizado; 2) formación en el síndrome X frágil. En su opinión, estos niños presentaban una serie de necesidades educativas muy específicas, diferentes a las mostradas por niños con otras discapacidades. Estas diferencias son:

Tabla 3. Diferencias entre niños con SXF y con otras discapacidades

\begin{tabular}{|c|c|}
\hline $\begin{array}{c}\text { Necesidad de un plan de manejo de conducta. } \\
\text { Falta de respuesta consistente a los refuerzos. }\end{array}$ & $\begin{array}{c}\text { Elevada tendencia a la distracción. } \\
\text { Impulsividad más intensa que otros niños. }\end{array}$ \\
Agresividad. & Actitud defensiva a la estimulación táctil. \\
Elevado nivel de ansiedad. & Problemas de integración sensorial*. \\
Conducta excesivamente alerta. & Habilidades de comunicación pobres. \\
Necesidad de una supervisión constante. & \\
\hline
\end{tabular}

\footnotetext{
* La capacidad de integración sensorial es la habilidad para procesar la información que llega a través de los sentidos.
} 
Los principales objetivos específicos que deben considerarse en un programa de intervención temprana para niños con SXF son, en opinión de Hatton y sus colaboradores (2000), los siguientes:

Tabla 4. Objetivos específicos de un programa para niños con SXF

\begin{tabular}{|l|l|}
\hline \multicolumn{1}{|c|}{ Área } & \multicolumn{1}{c|}{ Objetivos específicos } \\
\hline Conducta & $\begin{array}{l}\text { Mejora de la atención. } \\
\text { Mejora de la obediencia y capacidad de participación en actividades dirigi- } \\
\text { das. } \\
\text { Reducción de las estereotipias. } \\
\text { Normalización de la conducta. } \\
\text { Reducir la actitud defensiva ante la estimulación sensorial. } \\
\text { Aumento de la habilidad para esperar los turnos. }\end{array}$ \\
\hline Social & $\begin{array}{l}\text { Aumento de las interacciones con otros niños. } \\
\text { Mejora de las habilidades sociales. } \\
\text { Mejora del juego simbólico. }\end{array}$ \\
\hline Lenguaje & $\begin{array}{l}\text { Aumento del lenguaje expresivo. } \\
\text { Respuesta adecuada a las preguntas. } \\
\text { Seguimiento de instrucciones. }\end{array}$ \\
\hline
\end{tabular}

\section{El sindrome de Williams}

Es una alteración debida a una microdeleción en el cromosoma 7 (7q11.23), que incluye el gen elastina. La mayoría de los casos resultan de una mutación de novo, aunque la condición se puede heredar de forma autosómica recesiva. $\mathrm{Su}$ frecuencia es, aproximadamente, de un caso por cada 25.000 nacimientos. Algunos autores han sugerido un perfil psicológico característico de las personas con síndrome de Williams (SW). El 95\% de los niños con SW tienen problemas de aprendizaje de ligeros a severos; el cociente intelectual medio oscila alrededor de 50. Hay una deficiencia ligera en el crecimiento prenatal; el desarrollo posnatal está un poco atrasado ( $75 \%$ de lo normal). En la primera infancia, los niños con SW suelen ser inquietos, con problemas de alimentación, con vómitos, y constipados frecuentes. El lenguaje puede desarrollarse lentamente en la etapa preescolar, pero en los años escolares las habilidades verbales son, en la mayoría de los casos, marcadamente superiores a las habilidades visoespaciales, y a las habilidades motoras gruesas 
y finas. La comprensión verbal de los niños con SW es bastante más limitada que su expresividad verbal. Su memoria auditiva, procesamiento verbal y el uso social del lenguaje están bien desarrollados. De hecho, presentan un buen nivel de vocabulario en los primeros años, con uso excesivo de frases estereotipadas. Los niños con SW muestran déficits significativos en la integración de la información visoperceptiva, en secuenciación, velocidad de ejecución, y habilidades motoras finas, en comparación con sus habilidades verbales y con otros grupos de niños igualados en CI verbal.

La mayoría de los niños con SW tienen escasas relaciones sociales con sus iguales, aunque son extravertidos, socialmente desinhibidos y muy afectuosos con los adultos. Manifiestan mayores tasas de problemas emocionales y de comportamiento que otros niños con problemas de desarrollo, con un temperamento difícil: hiperactividad, baja capacidad de adaptación, pobre concentración y tendencia a la distracción, conductas para llamar la atención, poca persistencia, y ansiedad generalizada (Udwin, 2002).

\section{El síndrome de Prader-Willi}

Es uno de los síndromes por microdeleción más comunes, una de las alteraciones más frecuentes en genética clínica, y la forma genética de obesidad conocida más común. El SPW está ocasionado por la falta de expresión de genes normalmente activos heredados del padre en el cromosoma 15, provocando una deleción (15q11.2). Su incidencia es de 1:10.00015.000 nacimientos, aproximadamente, dándose en ambos sexos y en todas las razas.

Desde el nacimiento a los 3 años, las principales características encontradas en todos los casos de SPW son: hipotonía, problemas de alimentación (a veces hay que recurrir a sonda nasogástrica o a otros métodos), aspecto dismórfico, hipoplasia genital y retraso en el desarrollo evolutivo (sedestación a los 12 meses; marcha a los 24 meses). Entre el 10\%-60\% de los niños con SPW presentan pobre actividad fetal, grito o llanto débil, letargia y temperamento inestable. La ganancia de peso excesivo puede empezar a aparecer hacia el final de esta etapa. Después de los 3 años, las características más comunes son: hipotonía, obesidad, dificultades de aprendizaje, estatura pequeña, dismorfia, e hipogonadismo, problemas de conducta: rabietas, testarudez, manifestaciones obsesivo-compulsivas, dificultad a los cambios en las rutinas, son frecuentes las mentiras, los hurtos y la conducta agresiva; 
hiperfagia debida a una anomalía hipotalámica. El desarrollo del lenguaje está atrasado, aunque con buen uso funcional. Las anomalías cognitivas son evidentes, con un retraso mental ligero: CI medio entre 60 y 70. Los niños con SPW presentan algunos puntos fuertes: habilidades viso-espaciales, lectura y memoria a largo plazo; sus puntos débiles son: aritmética, procesamiento secuencial y memoria a corto plazo (Holland, Whittington y Butler, 2002).

De todas estas observaciones, debidamente contrastadas empíricamente y en la práctica diaria, podemos deducir que la intervención no se puede basar, únicamente, en el estudio de los procesos normales del desarrollo, el cual describe cómo evolucionan los niños cuyos sentidos están intactos y cuyos cerebros funcionan con normalidad. Ninguna de estas suposiciones vale para los niños con problemas de desarrollo. Tener presentes las peculiaridades de estos niños supone una valiosa ayuda para que aprendan mejor las mismas cosas aunque por caminos diferentes. Parece, pues, que los programas educativos deben armonizarse con las necesidades específicas del niño (Gibson, 1991). Para ello, son necesarias dos cosas: $1^{\text {a }}$ ) Saber la forma en que el desarrollo del niño es diferente; y, $2^{\mathrm{a}}$ ) Adaptar el programa educativo a sus particularidades. No basta, por tanto, con plantear los objetivos de una forma secuenciada, en base al patrón del desarrollo evolutivo general, sin más; hay que tener presentes las características del niño, los aspectos cualitativos de sus comportamientos.

\section{Descripción de objetivos}

Partiendo de una concepción que contempla la globalidad del niño, y de la importancia primordial de las interacciones socio-afectivas de éste con el medio que le rodea, fundamentalmente la familia, tiene sentido abordar los objetivos del programa de AT. Al fin y a la postre, cualquier profesional de la AT necesita recurrir a determinadas habilidades que el niño debe ir adquiriendo. Los objetivos que aportamos a continuación corresponden a las cuatro áreas más tradicionales: motora, perceptivo-cognitiva, socio-comunicativa, y hábitos de autonomía. Han sido extraídos de varias fuentes (Vidal y Díaz, 1990; Candel, 1993; Sánchez Asín, 1997), y tienen una intención meramente orientadora. Es de sobra conocido que, a medida que se va adquiriendo experiencia, cada profesional va elaborando su propio currículo, con una mentalidad ecléctica. Quede claro que estos objetivos, que respetan el desarrollo evolutivo del niño normal, no deben ser contemplados como algo universal, sino 
que su aplicación estará condicionada por las características del niño y su familia. Han sido agrupados en cuatro intervalos de tres meses cada uno, hasta el año de vida; y en dos intervalos de seis meses hasta los 2 años. Estos intervalos de referencia constituyen indicadores que deben tomarse en relación con los niveles de desarrollo del niño objeto del programa.

Intervención en el área motora

A continuación recogemos los principales objetivos para estimular habilidades de motricidad gruesa en niños hasta los 2 años. Las edades de referencia constituyen meros indicadores que deben tomarse en relación con el nivel de desarrollo del niño.

Tabla 5. Principales objetivos para estimular habilidades de motricidad gruesa hasta los 2 años.

\begin{tabular}{|c|c|c|}
\hline 0-3 meses & 3-6 meses & 6-9 meses \\
\hline $\begin{array}{l}\text {-Estimulación de reflejos } \\
\text {-Favorecer los movimientos del } \\
\text { cuerpo } \\
\text {-Control cefálico en diferentes posi- } \\
\text { ciones } \\
\text {-Estimulación vestibular } \\
\text {-Volteos }\end{array}$ & $\begin{array}{l}\text {-Reforzamiento del control cefálico } \\
\text {-Control del tronco } \\
\text {-Apoyo en antebrazos en prono } \\
\text {-Iniciación a los desplazamientos en } \\
\text { prono } \\
\text {-Apoyo en manos } \\
\text {-Volteos } \\
\text {-Reacciones de equilibrio } \\
\text {-Toma de peso en pies } \\
\text {-Sedestación: inicio }\end{array}$ & $\begin{array}{l}\text {-Posición de rodillas } \\
\text {-Control del tronco } \\
\text {-Sedestación con apoyo } \\
\text {-Toma de peso en manos } \\
\text {-Rastreo } \\
\text {-Reacciones de equilibrio } \\
\text {-Sedestación sin apoyos } \\
\text {-Equilibrio en sedestación } \\
\text {-Mantenimiento en cuatro apoyos } \\
\text {-Marcha de rodillas. Gateo } \\
\text {-Cambios posturales } \\
\text {-Bipedestación } \\
\text {-Estimulación vestibular }\end{array}$ \\
\hline 9-12 meses & 12-18 meses & 18-24 meses \\
\hline $\begin{array}{l}\text {-Reforzar adquisiciones anteriores } \\
\text {-Bipedestación con apoyo } \\
\text {-Equilibrio en bipedestación } \\
\text {-Reacciones de equilibrio: caídas } \\
\text {-Marcha con ayuda } \\
\text {-Bipedestación sin apoyo } \\
\text {-Estimulación vestibular } \\
\text {-Marcha independiente }\end{array}$ & $\begin{array}{l}\text {-Perfeccionar los cambios postura- } \\
\text { les } \\
\text {-Perfeccionamiento de la marcha } \\
\text {-Equilibrio y coordinación general } \\
\text {-Subir y bajar escaleras } \\
\text {-Estimulación vestibular } \\
\text {-Marcha rápida }\end{array}$ & $\begin{array}{l}\text {-Reforzar y perfeccionar adquisi- } \\
\text { ciones } \\
\text {-Control del movimiento. Saltos } \\
\text {-Carrera } \\
\text {-Patear objetos } \\
\text {-Coordinación dinámica general }\end{array}$ \\
\hline
\end{tabular}


Es evidente que, en el caso de niños con notables problemas motores, como en la parálisis cerebral, el fisioterapeuta juega un papel de especial importancia en la rehabilitación de estos trastornos. En la intervención del desarrollo motor de los niños con hipotonía muscular, más concretamente niños con SD, el objetivo de la fisioterapia no es acelerar la velocidad del desarrollo, sino, más bien, restringir al máximo el desarrollo de patrones de movimientos compensatorios, que los niños con SD son propensos a desarrollar. En efecto, estos niños tratan de compensar su hipotonía, su hiperlaxitud ligamentosa, su menor fuerza, y la pequeñez de sus extremidades, desarrollando patrones de movimientos compensatorios que pueden acabar en problemas ortopédicos y funcionales (Winders, 2002).

\section{Intervención en el área perceptivo-cognitiva.}

Pensamos que un objetivo prioritario del programa de intervención temprana es que el niño esté conectado con su entorno, mostrando una buena capacidad de respuesta, y pueda influir adecuadamente sobre él. No obstante, una intervención en este área nunca será algo aislado; esta relación del niño con su medio físico pasa por una interacción con su entorno social, ya que existe una interdependencia entre las distintas parcelas del desarrollo y el niño es un todo global que recibe estímulos de cualquier tipo, y reacciona ante ellos.

Los niños con discapacidad manifiestan dificultades específicas en su relación con el medio físico, por lo que su conocimiento nos va a resultar muy útil a la hora de elaborar el programa de AT. Este área se revela como muy importante, toda vez que el aprendizaje en los

primeros años es, eminentemente, sensoriomotor, y, por ello, es fundamental procurar que el niño, ante todo, manifieste interés por el medio que le rodea y que interactúe adecuadamente con él. Y también que tenga adecuados niveles de manipulación y exploración de los materiales a su alcance; que sea capaz de ir resolviendo los pequeños problemas que se le van planteando en sus rutinas diarias, elaborando las estrategias apropiadas para ello; que pueda influir sobre el ambiente, provocando oportunidades de relación que van a tener una notable influencia en su desarrollo socio-afectivo. Los objetivos en este área son los siguientes: 
Tabla 6. Objetivos del área perceptivo-cognitiva

\begin{tabular}{|c|c|c|}
\hline & & \\
\hline $\begin{array}{l}\text {-Favorecer la exploración visual } \\
\text {-Fijación de la mirada y contacto } \\
\text { ocular } \\
\text {-Orientación a estímulos visuales } \\
\text {-Seguimiento visual } \\
\text {-Estimulación auditiva } \\
\text {-Respuestas de orientación a soni- } \\
\text { dos } \\
\text {-Estimular respuestas de habitua- } \\
\text { ción } \\
\text {-Reacción a estímulos aversivos } \\
\text {-Estimulación táctil } \\
\text {-Estimulación del olfato } \\
\text {-Desarrollo de esquemas } \\
\text {-Alternar la mirada } \\
\text {-Experimentación de las conse- } \\
\text { cuencias de sus propias acciones } \\
\text {-Estimulación vestibular } \\
\text {-Advertir la desaparición de per- } \\
\text { sonas u objetos de su campo vi- } \\
\text { sual } \\
\text {-Estimulación del reflejo de pren- } \\
\text {-Conciencia de su propio cuerpo: } \\
\text { manos la apertura de las ma- } \\
\text {-Estimular }\end{array}$ & $\begin{array}{l}\text {-Estimular la discriminación de diferen- } \\
\text { cias } \\
\text {-Mirar activamente alrededor } \\
\text {-Alternar la mirada ante varios objetivos } \\
\text {-Seguimiento de objetos que se despla- } \\
\text { zan rápidamente } \\
\text {-Localización de sonidos } \\
\text {-Prensión voluntaria } \\
\text {-Desarrollo de esquemas } \\
\text {-Permanencia del objeto } \\
\text {-Reconocimiento y exploración de su } \\
\text { cuerpo y de su propia imagen } \\
\text {-Comprensión de la relación de sus pro- } \\
\text { pias conductas sobre los objetos } \\
\text {-Repetición de acciones lúdicas intere- } \\
\text { santes para el niño } \\
\text {-Imitación de gestos y acciones sencillas }\end{array}$ & $\begin{array}{l}\text {-Seguimiento y búsqueda de obje- } \\
\text { tos que se desplazan rápidamente } \\
\text {-Manipulación y exploración de los } \\
\text { objetos } \\
\text {-Estimulación del uso de medios } \\
\text { para alcanzar un objetivo } \\
\text {-Permanencia del objeto } \\
\text {-Discriminación visual y auditiva } \\
\text {-Relaciones espaciales } \\
\text {-Estimular la anticipación de con- } \\
\text { ductas en el juego } \\
\text {-Perfeccionamiento de la prensión } \\
\text {-Desarrollo de esquemas } \\
\text {-Estimular las acciones del niño } \\
\text { sobre los objetos } \\
\text {-Estimular la conciencia del propio } \\
\text { cuerpo } \\
\text {-Imitación }\end{array}$ \\
\hline & & \\
\hline $\begin{array}{l}\text {-Relaciones causa-efecto } \\
\text {-Desarrollo de esquemas } \\
\text {-Relaciones espaciales del objeto } \\
\text {-Uso de medios para alcanzar un } \\
\text { objetivo } \\
\text {-Combinación de objetos } \\
\text {-Reconocimiento de objetos y } \\
\text { personas familiares }\end{array}$ & $\begin{array}{l}\text {-Mejorar la atención y la exploración } \\
\text {-Permanencia del objeto } \\
\text {-Estimular el control ambiental } \\
\text {-Estimular conceptos de tiempo } \\
\text {-Exploración del ambiente externo } \\
\text {-Relación causa-efecto } \\
\text {-Relación tamaño y espacio } \\
\text {-Uso de medios }\end{array}$ & $\begin{array}{l}\text {-Uso de medios } \\
\text {-Causalidad operacional } \\
\text {-Garabateo: imitación de trazos } \\
\text {-Coordinación óculo-manual } \\
\text {-Estimular la habilidad de solución } \\
\text { de problemas } \\
\text {-Permanencia del objeto } \\
\text {-Agrupar objetos }\end{array}$ \\
\hline
\end{tabular}




\begin{tabular}{|l|l|l|}
\hline -Permanencia del objeto & -Discriminación auditiva & -Iniciación a algunos conceptos \\
-Imitación & -Coordinación óculo-manual & -Estimulación táctil \\
-Discriminación de objetos fami- & -Relaciones espaciales & -Discriminación de sonidos \\
liares & -Reforzar la combinación de objetos & -Estimulación olfativa y gustativa \\
-Reconocimiento de sí mismo & -Garabateo & -Imitación \\
-Perfeccionamiento de la pren- & -Concepto de sí mismo \\
sión: pinza & -Pelaciones espaciales \\
-Juegos de agua & -Esquemas de acción: juego simbólico & \\
& -Imitación & \\
\hline
\end{tabular}

\section{Intervención en el área socio-comunicativa}

El área del lenguaje, especialmente en su faceta expresiva, es una de las principales dificultades de los niños con discapacidad, ya desde sus primeros años. Pero en el programa de AT debemos prestar también especial atención a las habilidades comunicativas, que deben aparecer en los niños desde sus primeros días de vida. Si en el apartado anterior hablábamos de la relación del niño con su medio físico, ahora nos hemos de referir a la relación del niño con su medio social.

En un programa de AT tiene una importancia decisiva la estimulación de las habilidades de comunicación del niño, y, por tanto, la implantación de una buena relación socio-afectiva entre los padres y su hijo, tema que abordaremos más adelante. La intervención en el área socio-comunicativa también contempla el lenguaje expresivo y comprensivo. Y, como se trata de una parcela especialmente deficitaria en el caso de los niños con discapacidad, conviene señalar que los padres no deben caer en el error de estar continuamente "estimulando" -más bien, "incordiando"- al niño, malinterpretando las indicaciones de los profesionales. Los niños muy pequeños, y en especial los que tienen alguna discapacidad, tienen unos cortos períodos de alerta; son esos momentos los que deben aprovecharse para interactuar con ellos, respetando los demás estados y no tratando de enviar mensajes a todas horas. El consejo de "hablar más a su hijo" debe entenderse como hable más al tiempo que ajusta el lenguaje para satisfacer el nivel de comprensión del lenguaje del niño, con el fin de facilitar el procesamiento del mensaje (Millar, Leddy y Leavitt, 2000). 
A veces los programas se centran mucho en mejorar, sin más, las habilidades lingüísticas del niño, sin tener en cuenta el valor del ambiente en que se desenvuelve el niño. Como acertadamente señala Gràcia (2003), los niños aprenden a hablar durante todas las horas del día en las que se llevan a cabo diversas actividades en lugares diferentes, con varias personas y con objetivos particulares. Una de estas actividades es el juego: los niños pasan muchas horas del día jugando, y no únicamente en solitario, sino con los padres, hermanos, abuelos, parientes, vecinos, iguales...; determinados tipos de juegos favorecen especialmente el desarrollo de la comunicación y el lenguaje. En efecto, conviene no olvidarse de influir sobre el entorno, de manera que la estimulación sea más rica y adaptada a las características del niño. Iacono, Chan y Waring (1998) estudiaron la eficacia de un programa de implementación de lenguaje para madres, cuyos hijos tenían entre 2;3 y 3;6 años. El análisis descriptivo de las conductas comunicativas de las madres indicó que, después del tratamiento, ellas tendían a dirigir más frases a sus hijos; utilizaban más modelos; usaban menos preguntas y frases directivas, y más estrategias, aunque limitadas, de enseñanza.

Desde los primeros días de vida, los tratamientos oral-motores deben formar parte de la intervención. Los resultados del trabajo de Kumin, Von.Hagen y Bahr (2001) sugieren que los niños pequeños con hipotonía muscular que recibían de forma continuada un tratamiento oral motor mejoraban su función motora para comer, beber y hablar. En este sentido, también se están revelando como muy eficaces las intervenciones que resaltan los puntos fuertes de algunos niños discapacitados, concretamente aquéllos que tienen mejores habilidades para el procesamiento de la información visual. Los programas de lenguaje-lectura, implantados desde los primeros meses, resultan un complemento muy válido dentro del programa de AT (Navarro y Candel, 1992; Troncoso, Del Cerro, Soler y otros, 1997; Candel, Navarro y Velandrino, 2004).

En la tabla siguiente recogemos algunos objetivos de intervención en el área sociocomunicativa durante los dos primeros años de vida:

Tabla 7. Objetivos del área socio-comunicativa

\begin{tabular}{|l|l|l|}
\hline \multicolumn{1}{|c|}{$\mathbf{0 - 3}$ meses } & \multicolumn{1}{|c|}{ 3-6 meses } & \multicolumn{1}{|c|}{ 6-9 meses } \\
\hline -Estimulación verbal y táctil & -Reforzar el contacto ocular y la fijación & -Comprensión social del \\
-Contacto ocular y fijación visual & de la mirada & medio \\
-Exposición a ambientes hogareños & -Discriminaciones visuales de referencia & -Conductas de juego \\
\hline
\end{tabular}




\begin{tabular}{|c|c|c|}
\hline $\begin{array}{l}\text {-Orientación a estímulos visuales y } \\
\text { auditivos } \\
\text {-Respuesta a estímulos aversivos } \\
\text {-Estimular la sonrisa social } \\
\text {-Establecimiento de pautas de interac- } \\
\text { ción padres-hijo } \\
\text {-Respuesta a estímulos aversivos } \\
\text {-Socio-comunicación }\end{array}$ & $\begin{array}{l}\text {-Reacciones ante el espejo } \\
\text {-Imitación } \\
\text {-Juegos y estímulos socio-emocionales } \\
\text {-Juegos de interacción } \\
\text {-Discriminación ambiental } \\
\text {-Intercambios comunicativos } \\
\text {-Adaptación social al medio }\end{array}$ & $\begin{array}{l}\text {-Expresiones emocionales } \\
\text {-Intercambios comunicativos } \\
\text {-Imitación } \\
\text {-Juegos de interacción } \\
\text {-Adaptación social }\end{array}$ \\
\hline 9-12 meses & 12-18 meses & 18-24 meses \\
\hline $\begin{array}{l}\text {-Miradas de referencia } \\
\text {-Comprensión de situaciones familia- } \\
\text { res } \\
\text {-Adaptación social y afectiva } \\
\text {-Imitación } \\
\text {-Juegos comunicativos y de interacción } \\
\text {-Comprensión de la prohibición } \\
\text {-Expresiones emocionales } \\
\text {-Comprensión verbal } \\
\text {-Expresión verbal: iniciación }\end{array}$ & $\begin{array}{l}\text {-Socialización } \\
\text {-Imitación gestual } \\
\text {-Comunicación } \\
\text {-Imitación vocal } \\
\text {-Comprensión verbal } \\
\text {-Expresión verbal }\end{array}$ & $\begin{array}{l}\text {-Socio-comunicación } \\
\text {-Imitación } \\
\text {-Comprensión } \\
\text {-Expresión verbal }\end{array}$ \\
\hline
\end{tabular}

Vamos a detenernos un poco a analizar la cuestión de la interacción padres-hijo, ya que en la actualidad es uno de los aspectos que está mereciendo mayor atención, sobre el que se ocupan muchos investigadores (Gràcia, 2003). Es bien sabido que las interacciones entre los padres y su hijo con discapacidad están muchas veces alteradas por las reacciones emocionales perturbadoras de los padres, que pueden disminuir su capacidad de reacción ante las manifestaciones del niño, inhibir su comportamiento interactivo en casos de depresión o de rechazo, o bien distorsionarlo cuando existen altos niveles de ansiedad (Fuertes y Palmero, 1995). A su vez, los niños suelen presentar dificultades para que se interpreten sus señales comunicativas: contacto ocular disminuido, menor capacidad de respuesta o mayor lentitud para responder a los estímulos, reacciones emocionales menos intensas, temperamento difícil en algunos casos (Candel, Carranza y Pérez, 1996; Spiker, Boyce y Boyce, 2002). El proceso interactivo padres-hijo ha sido especialmente analizado en el caso de los niños con síndrome de Down. Cardoso-Martins y Mervis (1985) opinan que las madres de los niños con SD sienten que sus hijos necesitan más dirección, pues son más pasivos y tienen menos interés que los niños no deficientes. Por su parte, Mahoney, Fors y Wood (1990) encontraron que las 
madres de niños con SD de 30 meses de edad cronológica no se diferenciaban de las madres de los niños normales en cuanto a producción de órdenes; sin embargo, estos autores encontraron algunas diferencias cualitativas: las madres de los niños con SD dirigían la atención de sus hijos en la misma proporción que las madres de los niños normales, pero sus requerimientos estaban menos relacionados con la actividad actual de sus hijos. Además, las madres de los niños con SD parecían centrarse menos en ayudar o apoyar la conducta actual de sus hijos y se ocupaban más en animarles a producir el nivel de conducta más alto que eran capaces de lograr. En consecuencia, las madres de los niños con SD percibían su rol, primariamente, como una ayuda a sus hijos para ejecutar todo su potencial durante la interacción. Por eso, a la hora de estudiar las interacciones entre los padres y sus hijos con $\mathrm{SD}$, se ha descrito a las madres de estos niños como más directivas y con roles más dominantes (McCollum y Hemmeter, 1997).

Como precisaron Crawley y Spiker (1983), la "directividad" y la sensibilidad de las madres de los niños con SD son dimensiones de estilo materno separables, siendo la "directividad" una dimensión aislada que no se relaciona con el desarrollo intelectual del niño o con otras cualidades maternas. Además, parece que las madres que combinan la sensibilidad y la "directividad", junto con el valor de la estimulación, pueden tener hijos con SD con una mayor competencia cognitiva. Trabajos más recientes insisten en que un estilo directivo no siempre está asociado al desarrollo más lento de los niños, y en las madres de niños con SD una estrategia directiva puede ayudar de manera decisiva a fijar las tareas y lograr que se terminen (Miller, Leddy y Leavitt, 2000). Tal vez lo que ocurre a las madres de los niños con $\mathrm{SD}$ es que, más que ser "directivas", presentan un estilo de interacción caracterizado por una mayor sensibilidad o capacidad de respuesta a las señales sociocomunicativas de sus hijos, sobre todo si éstas contienen vocalizaciones (Fischer, 1987). Esto es compatible con la hipótesis de que las madres de los niños con SD usan más los diversos controles, principalmente para apoyar y animar la participación de su hijo deficiente en la interacción (Tannock, 1988).

Uno de los principales propósitos de la educación de los niños con problemas evolutivos en sus primeros años, es, precisamente, favorecer un buen ajuste de los padres y fomentar unos adecuados patrones comunicativos, de forma que el niño se sienta más motivado para reaccionar a los estímulos del medio y, a su vez, sus padres disfruten más con su propio rol parental. Por tanto, un programa de AT debe tener en cuenta la calidad de esas 
interacciones, fomentando la relación padres-hijo y evitando la aparición de estilos interactivos inadecuados, con el fin de lograr los siguientes objetivos: a) Procurar que los padres inicien actividades y juegos placenteros con su hijo, para que éste se sienta más motivado y reaccione más y mejor, y para que aquéllos disfruten con su rol de padres; b) Desarrollar en los padres habilidades de observación para interpretar las señales de su hijo y, c) Aumentar y mejorar la comunicación de la díada padres-hijo.

Varios autores que han abordado esta cuestión han propuesto programas para mejorar la calidad de esas interacciones (Sandall, 1988; Mahoney y Powell, 1988; Clark y Seifer, 1983; Tannock, Girolametto y Siegel, 1992; Dodd, McCormack y Woodyatt, 1994; Warren, Poder, Gazdag y otros, 1993). Gràcia y del Río (2000) plantean unas pautas de intervención naturalista con las familias, que tienen lugar en el contexto natural del niño y que se basan en las estrategias que, de forma natural, utilizan los padres con sus hijos. Estas autoras sugieren una serie de actividades para la creación de rutinas interactivas, la adecuación del entorno y la mejora de las estrategias de interacción socio-comunicativa. Desde el inicio, es esencial que los niños se acostumbren a que en cada día hay un momento de juego con el padre o la madre. Pero se trata de un juego no impuesto, ni de cambiar del todo la manera de jugar establecida en cada familia (Gràcia, 2003).

Tabla 8. Pautas de intervención naturalista

\begin{tabular}{|c|c|c|}
\hline $\begin{array}{c}\text { CREACIÓN DE RUTINAS IN- } \\
\text { TERACTIVAS }\end{array}$ & ADECUACIÓN DEL ENTORNO & $\begin{array}{l}\text { ESTRATEGIAS DE INTERAC- } \\
\text { CIÓN }\end{array}$ \\
\hline $\begin{array}{l}\text { Jugar unos minutos cada día con el } \\
\text { niño. }\end{array}$ & $\begin{array}{l}\text { Jugar en un espacio iluminado, } \\
\text { tranquilo y cómodo. }\end{array}$ & $\begin{array}{l}\text { Observar y escuchar cómo se } \\
\text { comunica el niño. }\end{array}$ \\
\hline $\begin{array}{l}\text { Encontrar momentos dedicados } \\
\text { exclusiva-mente al niño. }\end{array}$ & $\begin{array}{l}\text { Colocar los juguetes o materiales de } \\
\text { juego al alcance del niño. }\end{array}$ & $\begin{array}{l}\text { Respetar el silencio del niño. } \\
\text { Seguir la iniciativa del niño: Imitar }\end{array}$ \\
\hline $\begin{array}{l}\text { Implicarse en actividades en las que } \\
\text { el niño lleve la iniciativa. }\end{array}$ & $\begin{array}{l}\text { Encontrar una posición de juego } \\
\text { cómoda. }\end{array}$ & $\begin{array}{l}\text { sus actos; interpretar sus actos. } \\
\text { Toma alternativa de turnos. }\end{array}$ \\
\hline $\begin{array}{l}\text { Encontrar momentos en los que les } \\
\text { apetece jugar a los padres y al niño. }\end{array}$ & $\begin{array}{l}\text { No preocuparse por el desorden de } \\
\text { los juguetes o materiales. }\end{array}$ & $\begin{array}{l}\text { Alargar las secuencias comunicati- } \\
\text { vas. }\end{array}$ \\
\hline
\end{tabular}

Nuestro programa de AT debe, pues, ayudar a los padres a que su estilo de interacción favorezca la aparición de pautas comunicativas adecuadas. Veamos algunas estrategias para ello: 
A. Reciprocidad. Se trata de favorecer las interacciones niño-cuidador sin objetos, como una parte del intercambio social: imitaciones recíprocas sin objeto. Este estilo también contempla que el cuidador haga alguna actividad física con el niño: lanzarlo al aire, balancearlo, etc. Aunque haya un contacto físico entre el niño y el cuidador, no se insiste para que el niño realice una determinada acción o conducta. Este estilo incluye intentos para que el niño siga desarrollando conductas que reflejan el papel activo del niño y del cuidador en el intercambio social. Ejemplos: jugar a las palmitas, al que te pillo; imitaciones recíprocas de vocalizaciones cuidador-niño...

B. Facilitación. La conducta verbal y no verbal del cuidador proporciona la estructura a la conducta del niño, y está diseñada para mantener al niño ocupado en una conducta o en un juego centrado en él, pero sin tratar de modificar, elaborar o volver a centrar su conducta. El cuidador proporciona ayuda al niño para que la conducta se mantenga. Ejemplos: recuperar un juguete que se ha caído o ha sido empujado fuera de su alcance; facilitar al niño la prensión de un juguete, dándole la vuelta; tener un juguete para que el niño lo pueda ver o jugar con él; ayudar al niño a jugar con un juguete, sujetándoselo; ayudarle a mirar un libro de imágenes.

C. Elaboración. El cuidador trata de modificar, elaborar y proporcionar información verbal y no verbal complementaria a lo que el niño está haciendo. Este estilo incluye conductas como demostrar o enseñar cómo puede usarse un juguete o un objeto, hacer preguntas, describir o enseñar aspectos de amplios contextos de la conducta del niño, etc. Sin embargo, no hay un intento claro de requerir o insistir en que el niño ejecute una conducta seleccionada por el adulto. Ejemplos: "mira lo que hace este juguete”; "imira lo que ha pasado!”; demostrar al niño una nueva forma de usar un juguete; “¿quieres tirarme la pelota?”

Los datos de que disponemos en la actualidad nos indican que la intervención en la interacción de los padres con sus hijos con discapacidad resulta eficaz en una doble dirección. En lo que respecta a los cambios experimentados en los padres, éstos mejoraban en una serie de variables: aumento de la capacidad de respuesta; mayor expresividad afectiva; organización del medio físico; implantación de un estilo más elaborador, con un descenso en la duración y frecuencia de las conductas controladoras (estimulación, toma de turnos), respetando más las iniciativas del niño. También se encontraron algunas relaciones funcionales entre los cambios en las conductas de los padres y las de los niños: aumento de las vocalizaciones, del contacto ocular y de algunos indicadores del desarrollo (McCollum y Hemmeter, 1997). En un amplio estudio longitudinal desde la infancia hasta los 10 años, 
Hauser-Cram, Warfield, Shonkoff y otros (2001) encontraron que la interacción madre-niño constituía un predictor clave del cambio en los resultados del niño y en el bienestar de los padres.

Los niños con daño cerebral o en situación de riesgo manifiestan a veces una conducta irritable debida en ocasiones a factores orgánicos (convulsiones, reflujo gastroesofágico, cólico infantil) y en otras a trastornos funcionales y de interacción: su comportamiento desorienta a los padres que no saben cómo actuar con el niño, por lo que sus acciones bienintencionadas para calmarlo resultan contraproducentes y aumentan la inestabilidad y la irritabilidad del pequeño (Girona, Bartolomé y Máñez, 2004). Podemos ofrecer a los padres una serie de consejos, adaptados a las características del niño y a las circunstancias familiares:

Tabla 9. Consejos para los padres adaptados a las características del niño y a las circunstancias familiares

\begin{tabular}{|c|c|}
\hline 1. Reconocer los estímulos estresantes. & $\begin{array}{l}\text { 2. Tratar al niño de forma pausada, manejarlo con } \\
\text { suavidad, dejarlo dormir el máximo tiempo posible sin } \\
\text { molestarle, protegerlo de la luz y del ruido, buscar la } \\
\text { posición de descanso en la que se encuentre más rela- } \\
\text { jado (apoyarlo en pañales o sabanitas enrolladas y } \\
\text { colocadas en pies y costados). }\end{array}$ \\
\hline $\begin{array}{l}\text { 3. Interactuar con el niño ligeramente cuando se des- } \\
\text { pierte, empleando un solo estímulo sensorial al mismo } \\
\text { tiempo para evitar la sobreestimulación; masajearlo } \\
\text { suavemente después del baño; ir sumando estímulos } \\
\text { poco a poco para comprobar su tolerancia. }\end{array}$ & $\begin{array}{l}\text { 4. Alimentarlo sin distracciones (televisión, radio, } \\
\text { música, mucha gente en la habitación). }\end{array}$ \\
\hline $\begin{array}{l}\text { 5. Tener bien establecidos los hábitos diarios que in- } \\
\text { cluyen regularidad en las comidas, las horas de sueño, } \\
\text { los paseos, los juegos... }\end{array}$ & $\begin{array}{l}\text { 6. Establecer un programa individualizado de cuida- } \\
\text { dos diarios, teniendo en cuenta las necesidades de los } \\
\text { padres y del entorno familiar cercano. }\end{array}$ \\
\hline $\begin{array}{l}\text { 7. Servir de apoyo a los padres estableciendo un siste- } \\
\text { ma de intercambio de información que sea flexible y } \\
\text { adecuado a las necesidades de la familia. }\end{array}$ & $\begin{array}{l}\text { 8. Favorecer la coordinación entre los distintos profe- } \\
\text { sionales que atienden al niño. }\end{array}$ \\
\hline $\begin{array}{l}\text { 9. Permitir a los padres expresar sus sentimientos res- } \\
\text { pecto al niño; darles tiempo para formular las pregun- } \\
\text { tas y asimilar la información recibida. }\end{array}$ & $\begin{array}{l}\text { 10. Proporcionar a los padres la seguridad de que van } \\
\text { a ser capaces de atender adecuadamente a su bebé, sin } \\
\text { marcarse objetivos a corto plazo. }\end{array}$ \\
\hline 11. Ofrecer y facilitar el contacto con otras familias. & $\begin{array}{l}\text { 12. Acudir al domicilio para conocer in situ el entorno } \\
\text { socio-familiar. }\end{array}$ \\
\hline $\begin{array}{l}\text { 13. Valorar la necesidad de apoyos familiares (econó- } \\
\text { micos, personal auxiliar...). }\end{array}$ & \\
\hline
\end{tabular}


Intervención para la adquisición de hábitos de autonomía personal

El principal objetivo a largo plazo de un programa de AT es desarrollar la capacidad de autonomía e independencia personal del niño con problemas de desarrollo, lo que le va a permitir afrontar por sí mismo las diversas situaciones que se le vayan presentando a lo largo de su vida. La estimulación de las habilidades de autonomía personal debe abordarse desde los primeros meses o años de vida, y constituye uno de los aspectos más espinosos, debido, por una parte, a la actitud superprotectora que suelen manifestar los padres y familiares del niño con dificultades en su desarrollo, y, por otra, a la tendencia a infravalorar las capacidades reales de estos niños.

La última revisión de la Asociación Americana para el estudio del retraso mental (AAVV, 2002a) ha vuelto a insistir en la importancia de la conducta adaptativa, que es el conjunto de habilidades conceptuales, sociales y prácticas que han sido aprendidas por las personas para funcionar en sus vidas corrientes. Existe en la actualidad un acuerdo importante en cuanto a que la estructura de la conducta adaptativa consiste en los siguientes tres grupos de factores: a) Cognitiva, Comunicación y Habilidades académicas (Habilidades conceptuales); b) Habilidades de competencia social (Habilidades sociales); y, c) Habilidades de vida independiente (Habilidades prácticas).

En la actualidad, está suficientemente demostrado que incluso los niños deficientes más afectados pueden aprender habilidades adaptativas básicas, ya que no existe una estrecha relación entre el desarrollo cognitivo y la autonomía personal. El aprendizaje por imitación y repetición, aunque no haya una interiorización de los contenidos, tiene una importancia decisiva en este asunto. La Escuela Infantil va a jugar en esta parcela una importancia decisiva.

A modo de orientación, ofrecemos en el siguiente cuadro algunas conductas-objetivo en las áreas de comida, control de esfínteres y vestido, en los primeros años: 
Tabla 10. Conductas-objetivo en las áreas de comida, control de esfínteres y vestido

\begin{tabular}{|c|c|}
\hline COMIDA & $\begin{array}{l}\text {-Mueve las mandíbulas y/o la lengua al tocarle los labios o la lengua. } \\
\text {-Al ver el alimento, hay una conducta de anticipación, con un aumento o disminución de la acti- } \\
\text { vidad: abre la boca, se inclina hacia la cuchara... } \\
\text {-Toma alimentos semisólidos. } \\
\text {-Con el labio superior puede quitar comida de la cuchara. } \\
\text {-Mastica cuando tiene alimento entre los dientes o encías, moviendo la lengua hasta donde está } \\
\text { colocado el alimento. } \\
\text {-Toma líquidos de un vaso usando el labio superior como ayuda para hacerlo. } \\
\text {-Se lleva a la boca galletas, rosquillas, pan y otros sólidos similares. } \\
\text {-Mordisquea sólidos blandos. } \\
\text {-Quita el alimento de la cuchara con un cierre completo de labios. } \\
\text {-Lleva el vaso a la boca (puede usar algún recurso adaptativo). } \\
\text {-Cuando sujeta el vaso bebe sin derramar líquido de la boca. } \\
\text {-Come con cuchara, aunque puede tener dificultad en mantener sobre ella el alimento. } \\
\text {-Pincha con un tenedor u otro objeto punzante. } \\
\text {-Mordisquea sólidos duros. } \\
\text {-Mastica, moviendo la lengua de lado a lado de la boca. } \\
\text {-Utiliza el cuchillo para extender o untar el pan. } \\
\text {-Come solo con cuchara derramando poco. } \\
\text {-Come con cuchara y tenedor, sin tirar apenas comida. } \\
\text {-Usa el cuchillo para presionar alimentos blandos. }\end{array}$ \\
\hline $\begin{array}{c}\text { CONTROL } \\
\text { DE ESFÍN- } \\
\text { TERES }\end{array}$ & $\begin{array}{l}\text {-Permanece seco durante dos horas. } \\
\text {-Tiene movimientos intestinales espontáneamente, a intervalos predecibles. } \\
\text {-Espontáneamente tiene un patrón de evacuación a intervalos predecibles. } \\
\text {-Indica mediante gestos, acciones o vocalizaciones que se ha hecho encima. } \\
\text {-Hace en el retrete o jarrito si se le mantiene durante unos minutos. } \\
\text {-Permanece seco si se le recuerda. } \\
\text {-Indica necesidad de ir al aseo mediante gestos, acciones o vocalizaciones. } \\
\text {-Permanece seco durante el día. } \\
\text {-Va al retrete sin que se le indique. } \\
\text {-Se limpia con papel. } \\
\text {-Permanece seco durante la noche. }\end{array}$ \\
\hline VESTIDO & $\begin{array}{l}\text {-Muestra conciencia de que se le está vistiendo: aumenta o disminuye el nivel de actividad. } \\
\text {-Ayuda en el vestido: estira o encoge brazos o piernas, levanta la cabeza... } \\
\text {-Tira de las prendas para quitárselas: calcetines, zapatos, ropa interior. } \\
\text {-Se quita algunas prendas: calcetines, pantalones... } \\
\text {-Se quita la camiseta, el jersey, la camisa desabotonada. } \\
\text {-Desabotona. } \\
\text {-Sube o baja una cremallera grande. } \\
\text {-Abotona. }\end{array}$ \\
\hline
\end{tabular}

Aspectos cualitativos para la ejecución del programa de AT.

Da la sensación de que el fin exclusivo de un programa de AT es que los niños consigan superar una serie de adquisiciones motoras, cognitivas o lingüísticas. Se puede pensar que intensidad es igual a eficacia: cuanto más se estimule al niño, mejor será su evolución en todos los aspectos. No es extraño, entonces, que los padres, llevados de un lógico afán por mejorar la deficiencia mental de su hijo, se dediquen en cuerpo y alma a esa tarea, produciéndose entonces una inversión de roles: llegan a convertirse en terapeutas de sus hijos con SD. Para muchos padres de niños con una deficiencia, sobre todo en esos primeros 
meses de ajuste a la situación, llega a ser muy difícil de resistir la tentación o el impulso de "trabajar" con su hijo más que "divertirse" con él. Cuando los padres se transforman en terapeutas o educadores de sus hijos deficientes, éstos pueden muy bien sentir que el amor que ellos necesitan está condicionado por la buena ejecución del juego que están realizando. Es muy triste que muchas de las alegrías que proporciona la paternidad o maternidad y la vida familiar, sean inicialmente percibidas por muchos padres como un tiempo perdido (Mason, 1995).

Bajo este enfoque, se prioriza además la intervención que se lleva a cabo en el centro de estimulación, procurando que el niño reciba el mayor número posible de sesiones. No voy yo a poner en duda el enorme valor de las sesiones individuales en un centro especializado, pero creo que su importancia es relativa y está muy condicionada por la implicación de los padres y de toda la familia en la educación del niño, que pasa la mayor parte del tiempo en su hogar, rodeado de los suyos. Como apuntaba no hace mucho Jesús Flórez (2004), "la insistencia por aplicar ejercicios agotadores, omnipresentes y omnicomprensivos de actividad física y estimulación sensorial es tal, que acorrala a los padres y los acongoja en su deseo de ofrecer al hijo todo lo que les dicen que es necesario. Debemos saber que la plasticidad funciona pero que tiene un límite, y que es contraproducente tratar de superarlo a costa de un desequilibrio en el desarrollo de toda la propia persona en su conjunto, y de la unidad en la que esa persona se encuentra: la familia. Debemos saber que el exceso de estímulos, o el desorden en su aplicación, provocan confusión en los sistemas". Es decir, la intervención temprana no es cuestión solamente de cantidad, sino de calidad.

En efecto, tratar de reducir los efectos de una deficiencia sobre el conjunto global del desarrollo del niño es un objetivo de cualquier programa de AT, y así tratamos de mejorar sus habilidades en todas las áreas; pero no podemos olvidarnos de otros aspectos de enorme importancia. No interesa tanto la adquisición de conocimientos y habilidades por parte del niño, sino una buena integración socio-comunicativa y la aprehensión de estrategias de solución de problemas y de autonomía personal y social, cara a un funcionamiento independiente el día de mañana. Lo realmente importante en los primeros meses de vida del niño con SD es cuidar el ajuste de la familia a la nueva situación y procurar una buena relación padres-hijo, más que preocuparse por ofrecer a los padres largas listas de objetivos preacadémicos. 
A la hora de elaborar el programa de AT, hay que tener presentes una serie de aspectos generales, de índole cualitativa, que tienen enorme importancia y que van a constituir el marco de referencia de la intervención a cualquier edad.

Como el programa se va a llevar a cabo especialmente en el hogar, es conveniente que estas consideraciones sean asumidas por los padres desde el primer momento, ya que no podemos limitar el desarrollo del programa a una simple enumeración de objetivos y actividades muy concretos, sin más pretensiones que la consecución de una serie de habilidades que no tienen ninguna trascendencia ni proyección en el ambiente natural del niño, al ser trabajados muchas veces de una forma mecánica y artificial. Veamos algunos de estos criterios (Candel, 2003; AAVV, 2002b):

Hay que despertar el interés del niño por el medio que le rodea, procurando que se sienta interesado en interactuar con personas y objetos, influyendo sobre ellos. Hay que hablarle mirándolo a la cara y procurando que él mantenga su mirada; ofrecerle materiales y estímulos adecuados a la edad para que los observe, los manipule, los procese; hay que introducir novedades en esos materiales. Es aconsejable mantener al niño durante espacios de tiempo apropiados, en los lugares comunes de la casa, exponiéndole a los estímulos habituales del medio.

$>$ Conviene aprovechar las rutinas diarias para estimular al niño, fomentar los lazos afectivos y jugar con él: alimentación, baño, cambio de pañal, vestido...

> Los padres deben respetar los tiempos del niño: se deben aprovechar los momentos de alerta y receptividad para interactuar, y no estar continuamente estimulándolo.

$>$ Hay que procurar que los padres implanten desde el principio un adecuado patrón de interacción con su hijo, a fin de favorecer sus respuestas socio-comunicativas: balbuceos, sonrisa, risa, contacto ocular, fijación de mirada, atención y observación...

$>$ Es conveniente que los estímulos estén bien estructurados, de manera que no se someta al niño a un continuo bombardeo que sería contraproducente.

$>$ El medio físico debe diseñarse de forma que favorezca las respuestas del niño: iluminación, sonido, espacios, tiempos, materiales, entorno seguro.

$>$ Las actividades deben ser funcionales, es decir, deben servir para acciones cotidianas insertándose en ellas. 
Actividades y algunas cuestiones prácticas.

Investigaciones recientes han puesto en entredicho la utilidad y las posibilidades de generalización de las destrezas enseñadas a los niños en condiciones rigurosamente controladas y estructuradas, en las que tiende a minimizarse la flexibilidad y la adaptabilidad. Se critica también a los programas clásicos, basados en técnicas conductuales, el haber ayudado poco a los niños a desarrollar estrategias que lleven a la resolución de problemas y a la independencia, haciendo mayor hincapié en la enseñanza de respuestas específicas a estructuras impuestas por el adulto. Algunos autores han informado, por otra parte, que las familias que participaban en programas de AT, sobre todo si la intervención era muy intensiva, manifestaban un alto grado de estrés por la excesiva carga que suponía la educación y el cuidado de un niño con problemas.

Una posible causa de este fenómeno estriba en que muchos de estos programas se han centrado, casi exclusivamente, en el logro de actividades por parte del niño: que coja, que saque, que meta, que haga torres, que garabatee, que ande, que suba, que baje... Esto no quiere decir, en absoluto, que los principios del aprendizaje conductual no sigan siendo válidos en la aplicación de los programas de AT. De hecho, continúan empleándose y con una eficacia notable; pero el entrenamiento debe entrelazarse con las actividades diarias del niño. Tratar de mejorar los potenciales madurativos del niño es uno de los objetivos de un programa de AT, pero no el único. De forma especial, el programa de AT pretende enriquecer el medio en el que se va a desenvolver el niño con dificultades en su desarrollo, fomentando las interacciones con las personas que le rodean. A largo plazo, el objetivo es que el niño se desenvuelva con el mayor grado de autonomía posible el día de mañana, para lo cual debe tener unos fundamentos adecuados.

En la actualidad, los programas de AT siguen una orientación basada en los modelos ecológico y transaccional, de forma que se enfatiza la atención global al niño, a su familia y a su entorno de una forma natural, empleando actividades funcionales que se inserten en las rutinas diarias del niño y de su familia. La adquisición del conocimiento y aprendizaje de habilidades debe darse en unas condiciones que sean auténticas, es decir el conocimiento o la habilidad es necesario o útil al ocuparse en tareas o problemas reales. Las situaciones 
auténticas para los niños deben incluir actividades que reflejen la realidad y las demandas de su vida diaria. Estas actividades permiten a los niños aprender y practicar habilidades que mejorarán su habilidad para adaptarse a los continuos requerimientos de su ambiente físico y social.

La naturaleza de las experiencias transaccionales que se dan entre los niños y su medio ambiente es fundamental para lo que ellos aprenden y cómo lo aprenden. Las experiencias o las actividades no sólo deben ser funcionales y reflejar la realidad de los niños, sino que también deben ser adecuadas desde el punto de vista evolutivo. Esto significa que las experiencias y las actividades deben estructurarse de forma que se presenten al niño con una moderada novedad. Los niños deben tener en su repertorio las conductas necesarias para participar significativamente en una actividad. Hay que estimular, pues, habilidades funcionales y generadoras. Las primeras son aquéllas que permiten al niño negociar con su medio físico y social de una forma independiente y satisfactoria, para ellos mismos y para otros, en su medio social. Hay que ayudar a los niños a adquirir habilidades generadoras: no basta con enseñar a los niños a responder a señales específicas bajo condiciones determinadas, sino más bien en desarrollar habilidades generalizadas en todas las áreas para permitir un funcionamiento independiente.

A la hora de proponer las actividades para conseguir los objetivos del programa de AT, conviene procurar que sean, simplemente, rutinas y juegos propios de los padres con sus hijos pequeños, con la intención de favorecer la interacción y la maduración del niño en el medio que le resulta familiar y con aquello que tiene a mano cada día. Es decir, que las actividades deben ser funcionales: servir para acciones cotidianas insertándose en ellas. De poco nos sirve entrenar a un niño a hacer cosas de forma mecánica en una situación artificial y con instrumentos poco naturales, si luego no es capaz de resolver las situaciones que se le van a presentar cada día en su casa, en el parque, en la Escuela Infantil, en sus juegos. Por tanto, antes que provocar respuestas específicas a estímulos muy prefijados, los profesionales tenemos que ayudar a construir clases de respuestas generadoras que lleven a un funcionamiento independiente y a habilidades de solución de problemas. Y todo ello en un contexto natural, aprovechando los momentos propicios (baño, vestido, alimentación, paseo, etc.), lo cual permitirá al niño ser más espontáneo y generalizar más sus aprendizajes. 
En el programa de AT podemos recurrir a tres tipos de actividades: rutinarias (que ocurren regularmente), planificadas (no suelen ocurrir normalmente si no son diseñadas), y actividades iniciadas por el niño. Estos tres tipos de actividades se combinan. La actividad en sí misma no es lo importante; lo fundamental es la oportunidad para practicar las habilidades. Siempre que sea posible, la intervención debe hacerse en las actividades de la vida diaria del niño. El uso de actividades diarias y de juego ayuda mucho a los niños a desarrollar respuestas útiles y generalizables. De otro lado, las actividades rutinarias ofrecen oportunidades para incorporar a la intervención habilidades que proporcionan una utilidad inmediata para el niño, poniendo a su alcance un objeto o acción útil o deseado. La incorporación de actividades rutinarias al programa de AT asegura oportunidades frecuentes y prácticas para desarrollar habilidades. Parece que aprender a expresar necesidades en condiciones naturales y relevantes conduce a un aprendizaje eficaz y eficiente.

Las actividades iniciadas por el propio niño llamarán y mantendrán más su atención e interés. Teniendo en cuenta la importancia fundamental que tienen los intereses y la motivación del niño, en lugar de actividades seleccionadas por los padres o el estimulador, se deben identificar los intereses del niño, y luego el adulto interactúa y juega con él a lo que éste ha seleccionado. El uso de actividades planificadas debe hacerse como una extensión natural de lo que a los niños les gusta hacer, y no como una experiencia de entrenamiento separada o fragmentada, no ligada a sus necesidades y conocimientos diarios (Candel, 2003). En resumen, hemos de procurar:

*Permitir al niño iniciar actividades, siempre que sea posible.

* Seguir la iniciativa del niño a menos que su conducta o actividad sea demasiado repetitiva, regresiva o se aparte de los objetivos propuestos.

*Introducir actividades planificadas que sean significativas para los niños.

*Controlar la implicación y el interés del niño en las actividades, y cambiar o introducir las adaptaciones pertinentes cuando la motivación decaiga.

* Observar constantemente la conducta de los niños y presentar oportunidades para mejorar sus habilidades de solución de problemas.

El programa de AT debe basarse en el contexto natural del niño y, en consecuencia, hay que diseñar de forma coherente ese medio físico y social, de manera que sea rico en estímulos para favorecer el desarrollo del niño y el buen equilibrio de la familia. Lo más importante no es 
tanto la adquisición de habilidades por parte del niño, cuanto una buena integración sociocomunicativa y la aprehensión de estrategias de solución de problemas y de autonomía personal y social, con vistas a un funcionamiento independiente el día de mañana.

Carece de sentido dar a los padres, para hacer en casa, listas de objetivos y actividades que muchas veces son demasiado artificiales, que no suelen tener una proyección real o práctica en la realidad, y que resultan, a la larga, inútiles para los niños y, en no pocas ocasiones, frustrantes y agobiantes para los propios padres. Generalmente, se espera que los padres de los niños deficientes encuentren tiempo para trabajar con sus hijos de una forma diferente a la de los niños normales. Para algunas familias, la enseñanza en el hogar es algo ideal, pero para otras es fuente de ansiedad y estrés, sobre todo si tienen otros niños pequeños a los que atender.

Dentro del programa de AT, un aspecto muy importante es el diseño del ambiente fisico del hogar. Como el niño va a vivir en casa con su familia, hemos de procurar que ese contexto sea favorecedor para su desarrollo. Podemos diseñar un programa de intervención fantástico, con sesiones en el centro impartidas por grandes profesionales, pero si descuidamos los aspectos familiares y los del hogar, todo eso puede quedar en papel mojado.

Se ha dicho que el ambiente en que se desenvuelve el niño debe ser sensorialmente rico y variado, fomentando su movilidad y su capacidad de exploración para evitar habituaciones que serían perjudiciales, tanto desde el punto de vista cognitivo como socio-comunicativo y adaptativo. Conviene aclarar que un ambiente rico en estímulos no significa, en absoluto, un medio excesivamente estimulante que bombardea al niño ofreciéndole actividades y materiales de una forma artificial y machacona. La estimulación debe ser estructurada y racional, para permitir al niño filtrar y seleccionar los estímulos del exterior. De otro modo, los efectos serían contraproducentes ya que el niño llega a hastiarse de tanto mensaje, siendo incapaz de responder de forma adecuada.

Dentro del apartado del ambiente físico del hogar, hay que hacer una mención especial al capítulo de los juegos, juguetes y materiales que el niño tiene a su alcance. Estos deben ser variados y adecuados a las características evolutivas y a los gustos personales de cada niño. No hay que caer en la tentación de hacer del hogar un segundo centro de estimulación, comprando al niño los mismos materiales que se le presentan en las sesiones impartidas en el 
Centro. En los juegos espontáneos entre los padres y el niño es donde se pueden y se deben insertar, de forma natural, los objetivos y las actividades del plan de estimulación: hay juegos que favorecen la interacción socio-comunicativa; juegos encaminados a mejorar la permanencia del objeto; juegos para favorecer la estimulación vestibular; juegos que desarrollan la actividad simbólica, etc. Lo fundamental es que los padres se diviertan mientras juegan con su hijo, haciendo atractivas estas actividades y no convirtiendo la estimulación en algo rígido, mecánico y tedioso para unos y otros.

Con el fin de conocer mejor este ambiente físico, y poder así ayudar a adaptarlo adecuadamente para el niño y su familia, un programa de AT debe contemplar la posibilidad de hacer visitas domiciliarias que permitan cumplir ese cometido. Tal vez lo más correcto, si no hay circunstancias que aconsejen lo contrario, sería que el programa, al menos durante los primeros seis-doce meses de vida del niño, se basara, exclusivamente o de forma prioritaria, en el hogar.

\section{Referencias}

AAVV (2002a). Mental Retardation. Definition, Classification, and Systems of Supports. Washington: American Association on Mental Retardation.

AAVV (2002b). Criterios de calidad estimular para la población infantil de 0 a 3 años. $R e-$ vista de Atención Temprana, $V(1), 4-20$.

Aylward, G.P. (1994). Update on early developmental neuropsychologic assessment: The Early Neuropsychologic Optimatily Rating Scales (ENORS). En M.G. Tramontana y S.R. Hooper (eds.), Advances in Child Neuropsychology Vol. 2 (pp. 172-200). Berlín: Springer-Verlag.

Aylward, G.P. (1995). The Bayley Infant Neurodevelopmental Screener Manual. San Antonio: The Psychological Corporation.

Aylward, G.P. (1997). Infant and Early Childhood Neuropsychology. New York: Plenum Press. Barnard, K.E. y Kelly, J.F. (1990). Assessment of parent-child interaction. En S.J. Meisels y J.P. Shonkoff (eds.), Handbook of Early Childhood Intervention (pp. 278-302). New York: Cambridge University Press.

Beckman, P.J. Frank, N. y Newcomb, S. (1996). Qualities and skills for communicating with families. En P. Beckman, (ed.), Strategies for working with families of young children with disabilities (pp.31-46). Baltimore: Paul H. Brookes. 
Buceta, M.J. y Fernández, J.C. (2004). Atención temprana en deficiencia mental y síndrome de Down. En J. Pérez-López y A.G. Brito (coords.), Manual de Atención Temprana (pp. 275-291). Madrid: Pirámide.

Candel, I. (dir.) (1993). Programa de atención temprana. Intervención en niños con síndrome de Down y otros problemas de desarrollo. Madrid: CEPE.

Candel, I. (2003). Elaboración del programa de atención temprana. En I. Candel (dir.), Atención Temprana. Niños con síndrome de Down y otros problemas del desarrollo (pp. 29-55). Madrid: FEISD.

Candel, I. (2004). Desarrollo evolutivo de los niños con síndrome X frágil en sus primeros años de vida. Programas de atención temprana. Revista Síndrome X Frágil, 5, 8-13.

Candel, I. (2005a). Evaluación social y familiar. Ponencia presentada a las II Jornadas de Atención Temprana Universidad Miguel Hernández "Estrategias de evaluación en la atención temprana”. Elche, 25-27 de abril.

Candel, I. (2005b). Síndrome de Down. En M.G. Millá y F. Mulas (dirs.), Atención Temprana. Desarrollo infantil, diagnóstico, trastornos e intervención (pp. 683-708). Valencia: Promolibro.

Candel, I. y Carranza, J.A. (1993). Características evolutivas de los niños con síndrome de Down en la infancia. En I. Candel (dir.), Programa de atención temprana. Intervención en niños con síndrome de Down y otros problemas de desarrollo (pp. 55-87). Madrid: CEPE.

Candel, I., Carranza, J.A. y Pérez, J. (1996). Socio-affective development in infants with Down syndrome. En J.A. Rondal, J. Perera, L. Nadel y A. Comblain (eds.), Down's syndrome. Psychological, Psychobiological and Socio-Educational Perspectives (pp. 165-177). London: Whurr Publishers.

Candel, I., Navarro, J. y Velandrino, A. (2004). Resultados de la aplicación de un programa de lenguaje-lectura para niños con síndrome de Down. En Educar para la vida. Actas del Congreso Nacional de Educación para personas con síndrome de Down (pp. 463470). Córdoba: Obra Social y Cultural CAJASUR.

Cardoso-Martins, C. y Mervis, C.B. (1985). Maternal speech to prelinguistic children with Down syndrome. American Journal of Mental Deficiency, 89, 451-458.

Cicchetti, D. y Wagner, S. (1990). Alternative assessment strategies for the evaluation of infants and toddlers: An organizational perspective. En S.J. Meisels y J.P. Shonkoff (eds.), 
Handbook of Early Childhood Intervention (pp.246-277). New York: Cambridge University Press.

Clark, G.N. y Seifer, R. (1983). Facilitating mother-infant communication: A treatment model for high-risk and developmentally-delayed infants. Infant Mental Health Journal, 4 (2), $67-82$.

Crawley, S.B. y Spiker, D. (1983). Mother-child interactions involving two-year-olds with Down syndrome: a look at individual differences. Child Development, 54, 1312-1323.

Dodd, B., McCormack, P. y Woodyatt, G. (1994). Evaluation of an intervention program: Relation between children's phonology and parents' communicative behavior. American Journal on Mental Retardation, 98, 632-645.

Dunst, C.J. (1990). Sensorimotor development of infants with Down syndrome. En D. Cicchetti y M. Beeghley (eds.), Down Syndrome. The Developmental Perspective (pp. 180-230). New York: Cambridge University Press.

Dunst, C.J. (1998). Sensorimotor development and developemental disabilities. En J.A. Burack, R.M. Hodapp y E. Zigler (eds.), Handbook of Mental Retardation and Development (pp. 135-182). NewYork: Cambridge University Press.

Fischer, M.A. (1987). Mother-child interaction in preverbal children with Down syndrome. Journal of Speech and Hearing Disorders, 52, 179-190.

Flórez, J. (2004). Bases neurobiológicas de la atención temprana. IV Congreso Andaluz Síndrome de Down De la atención temprana a la escuela. Sevilla, 19-21 de noviembre.

Fuertes, J. y Palmero, P. (1995). Intervención temprana. En M.A. Verdugo (dir.), Personas con discapacidad. Perspectivas psicopedagógicas y rehabilitadoras (pp. 925-970). Madrid: Siglo XXI.

Gibson, D. (1991). Down syndrome and cognitive enhancement: not like the others. En K. Marfo (ed.), Early Intervention in Transition (pp. 61-90). New York: Praeger.

Girona, G., Bartolomé, C. y Máñez, I. (2004). Causas de irritabilidad en el lactante con daño cerebral. Revista de Atención Temprana, VII (1), 22-30.

Gràcia, M. (2003). Comunicación y lenguaje en primeras edades. Intervención con familias. Lérida: Milenio.

Gràcia, M. y del Río, M.J. (2000). Intervención naturalista en la comunicación y el lenguaje para familias de niños pequeños con síndrome de Down. Revista síndrome de Down, 64, 17 (1), 2-14. 
Greenberg, M.T. y Crnic, K.A. (1988). Longitudinal predictors of developmental status and social interaction in premature and full-term infants at age two. Child Development, 59, 554-570.

Hatton, D.D., Bailey, D.B., Roberts, J.F., Skinner, M., Mayhew, L., Clark, R.D., Waring, E. y Roberts, J.E. (2000). Early intervention services for young boys with fragile X syndrome. Journal of Early Intervention, 23 (4), 235-251.

Hauser-Cram, P., Warfield, M.E., Shonkoff, J.P., Krauss, M.W., Sayer, A., y Upshur, C.C. (2001). Children with disabilities: a longitudinal study of child development and parent well-being. Monographs of the Society for Research in Child Development, 66 (3), i-viii, 1-114.

Holland, A., Whittington, J. y Buttler, J. (2002). Prader-Willi and Angelman syndromes: from childhood to adult life. En P. Howlin y O. Udwin (eds.), Outcomes in neurodevelopmental and genetic disorders (pp. 220-240). Cambridge: Cambridge University Press.

Hodapp, R.M. y Dykens, E.M. (2004). Genética y fenotipo conductual en la discapacidad intelectual: su aplicación a la cognición y a la conducta problemática ( $1^{\mathrm{a}}$ Parte $)$. Revista Sindrome de Down, 21, 134-149.

Iacono, T., Chan, J. y Waring, R. (1998). Efficacy of a parent implemented early language intervention based on collaborative consultation. International Journal of Language and Communication Disorders, 33 (3), 281-303.

Korkman, M., Kirk, U. y Kemp, S. (1997). NEPSY. San Antonio: The Psychological Corporation.

Krauss, M.W. (2000). Family assessment within early intervention programs. En J.P. Shonkoff y S.J. Meisels (eds.), Handbook of Early Childhood Intervention (pp. 290-308)). New York: Cambridge University Press.

Kumin, L., Von-Hagel, K. y Bahr, D. (2001). An effective oral motor intervention protocol for infants and toddlers with muscle tone. Infant Toddler Intervention, 11 (3-4), 181200.

Linn, M., Goodman, J. y Lender, W. (2000). Played out? Passive behavior by children with Down syndrome during unstructured play. Journal of Early Intervention, 23 (4), 264278.

Mahoney, G., Fors, S. y Wood, S. (1990). Maternal directive behavior revisited. American Journal on Mental Retardation, 94 (4), 398-406. 
Mahoney, G. y Powell, A. (1988). Modifying parent-child interaction: enhancing the development of handicapped children. The Journal of Special Education, 22 (1), 8296.

Mason, M. (1995). The Breaking of Relationships. Present Time, January, 10-15.

McCollum, J.A. y Hemmeter, M.L.. (1997). Parent-child interaction intervention with children have disabilities. En M.J. Guralnick (ed.), The Effectiveness of Early Intervention (pp. 549-576). Baltimore: Paul H. Brookes.

McCune, L., Kalmanson, B., Fleck, M.B., Glazewski, B. y Sillari, J. (1990). An interdisciplinary model of infant assessment. En S. J. Meisels y J. P. Shonkoff (eds.), Handbook of Early Childhood Intervention (pp. 219-245). New York: Cambridge University Press.

Meisels, S.J. y Atkins-Burnett, S. (2000). The elements of early childhood assessment. En J.P. Shonkoff y S.J. Meisels (eds.), Handbook of Early Childhood Intervention (pp. 231257). New York: Cambridge University Press.

Miller, J.F., Leddy, M. y Leavitt, L.A. (2000). Mejorar la comunicación de personas con síndrome de Down. Revista Síndrome de Down, 17, 102-108.

Navarro, F. y Candel, I. (1992). Un programa de lenguaje-lectura para niños con síndrome de Down. En I. Candel y A.Turpín (dirs.), Síndrome de Down. Integración escolar y laboral (pp. 297-328). Murcia: ASSIDO.

Roberts, J.E., Hatton, D.D. y Bailey, D.D. (2001). Development and behaviour of male toddlers with fragile X syndrome. Journal of Early Intervention, 24 (3), 207-223.

Ruskin, E.M., Mundy, P., Kasari, C, y Sigman, M. (1994a). Object mastery motivation of children with Down syndrome. American Journal on Mental Retardation, 98 (4), 499509 .

Ruskin, E.M., Kasari, C., Mundy, P. y Sigman, M. (1994b). Attention to people and toys during social and object mastery in children with Down syndrome. American Journal on Mental Retardation, 99 (1), 103-111.

Sánchez Asín, A. (1997). Atención temprana. Programa de 0 a 3 años. Barcelona: Cedecs.

Sandall, S.R. (1988). Parent-child interaction: learning to take turns. En V. Dmitriev y P.L. Oelwein (eds.), Advances in Down syndrome (pp. 261-269). Seattle: Special Child Publications.

Spiker, D., Boyce, G. y Boyce, L. (2002). Parent-child interactions when young children have disabilities. En L. Glidden (ed.), International review of research in mental retardation, Vol. 25 (pp. 35-70). San Diego: Academic Press. 
Tannock, R. (1988). Mother's directiveness in their interactions with their children with and without Down syndrome. American Journal of Mental Deficiency, 93, 154-165.

Tannock, R., Girolametto, L. y Siegel, L.S. (1992). Language intervention with children who have developmental delays: Effects of an interactive approach. American Journal on Mental Retardation, 97, 145-160.

Troncoso, M.V., Del Cerro, M., Soler, M. y Ruiz, E. (1997). Fundamentos y resultados de un método de lectura para alumnos con síndrome de Down. En J. Flórez, M.V. Troncoso y M. Dierssen (dirs.), Síndrome de Down: Biología, Desarrollo y Educación. Nuevas perspectivas (pp. 187-199). Barcelona: Masson.

Udwin, O. (2002). Williams and Smith-Magenis syndromes. En P. Howlin y O. Udwin (eds.), Outcomes in neurodevelopmental and genetic disorders (pp. 299-324). Cambridge: Cambridge University Press.

Vidal, M. y Díaz, J. (1990). Atención temprana. Guía práctica para la estimulación del niño de 0 a 3 años. Madrid: CEPE.

Warren, S.F., Yoder, P., Gazdag, G.E., Kim, K. y Jones, H.A.(1993). Facilitating prelinguistic communication skills with young children with developmental delay. Journal of Speech and Hearing Research, 36, 83-97.

Winders, P.C. (2002). Objetivos y oportunidades de la fisioterapia para los niños con síndrome de Down. Revista Síndrome de Down, 19, 2-7.

Wishart, J. (1997). Aprendizaje en niños pequeños con síndrome de Down: tendencias evolutivas. En J.A. Rondal, J. Perera, L. Nadel y A. Comblain (dirs.), Síndrome de Down: Perspectivas psicológica, psicobiológica y socio-educacional (pp.119-137). Madrid: IMSERSO.

Wishart, J. (2002). Learning in young children with Down syndrome: Public perceptions, empirical evidence. En M. Cuskelly, A. Jobling y S. Buckley (eds.), Down syndrome across the life span (pp. 18-27). London: Whurr Publishers. 